\title{
Biochar-based cement pastes and mortars with enhanced mechanical properties
}

\author{
Alice Sirico, Patrizia Bernardi, Beatrice Belletti, Alessio Malcevschi \\ University of Parma, Italy \\ alicesirico@unipr.it, bttps://orcid.org/0000-0001-5897-1641 \\ patrizia.bernardi@unipr.it,bttps://orcid.org/0000-0003-0554-5870 \\ beatrice.belletti@unipr.it, https://orcid.org/0000-0002-4382-9930 \\ alessio.malcevschi@unipr.it,bttp://orcid.org/0000-0001-9035-5865 \\ Luciana Restuccia, Giuseppe Andrea Ferro, Daniel Suarez-Riera \\ Politecnico di Torino, Italy \\ luciana.restuccia@polito.it, bttps://orcid.org/0000-0002-6999-0466 \\ ferro@polito.it, https://orcid.org/0000-0002-0622-4203 \\ daniel.suarez@polito.it, bttps://orcid.org/0000-0002-3955-9683
}

ABSTRACT. Nowadays, the environmental impact of cementitious material industry and more generally of building activities is matter of concern, especially in terms of their effects on climate change and consumption of natural resources. Within this context, the aim of this paper is the investigation of the role of biochar, a solid carbonaceous by-product material resulting from biomass pyrolysis/gasification of residual biomass, as a sustainable ingredient for the production of cementitious materials, combining carbon sink properties with enhanced mechanical behavior. Although biochar is mainly investigated as agricultural amendment, there is also evidence that biochar may be an eco-friendly material to improve the sustainable performance of cementitious materials.

As outlined in literature, biochar can be used as filler to modify the nanogranular nature of cement matrix, or as substitute of clinker to reduce the emissions of greenhouse gases related to cement production. In this work, biochar is added as micro-nano particles in different cementitious composites, i.e. cement pastes and mortars, as a function of filler or partial substitute of cement. The main mechanical properties of biochar-based materials are then investigated to determine the optimal percentage of biochar addition.

KEYWORDS. Biochar; Nanoparticles; Cement-based composites; Strength; Toughness; Digital Image Correlation.

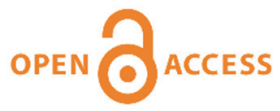

Citation: Sirico, A., Bernardi, P., Belletti, B., Malcevschi, A., Restuccia, L., G.A. Ferro, Suarez-Riera, D., Biochar-based cement pastes and mortars with enhanced mechanical properties, Frattura ed Integrità Strutturale, 54 (2020) 297-316.

Received: 07.08.2020

Accepted: 11.09 .2020

Published: 01.10.2020

Copyright: (C) 2020 This is an open access article under the terms of the CC-BY 4.0, which permits unrestricted use, distribution, and reproduction in any medium, provided the original author and source are credited. 


\section{INTRODUCTION}

7 he high rates of greenhouse gas emissions have led to the need for measures to mitigate the damage caused and reduce future emissions. In the construction industry, concrete is the most used material in the world, thanks to its low cost and mechanical benefits; currently, more than $2.8 \mathrm{bn}$ tons of concrete are consumed each year [1]. Due to the large quantities involved, the cement industry accounts for $7 \%$ of global $\mathrm{CO}_{2}$ emissions[2]. These levels have raised alarm and led to finding more environmentally friendly alternatives.

Recently, many opportunities for using alternative cements are based on different chemical compositions and binding phases and they are obtained using recycled resources and mineral waste [3]. Today Supplementary Cementitious Materials (SCMs) are also widely used in concrete technology to partially substitute ordinary Portland cement (OPC). Given that there is no additional clinkering process involved, their use leads to a significant reduction in $\mathrm{CO}_{2}$ emissions per ton of cementitious materials $[4,5]$. Some of the emerging green alternatives rely on technological advances that include energy-efficiency and low carbon production methods or new cement formulations as calcium sulfoaluminates cements (CSA), geopolymers and carbon negative cements. Alternative Cementitious Materials (ACMs) concretes can be produced with greenhouse gases (GHG) emissions and energy consumption significantly lower than mixtures comprising Portland cement [6-8].Another possibility of action is based on the use of biochar in cement-based materials.

The International Biochar Initiative (IBI) defines biochar as "a solid material obtained from the thermochemical conversion of biomass in an oxygen-limited environment" [9]. Over the year 2016, the European Union generated almost 50 million tons of wood wastes, of which $48 \%$ were combusted with energy recovery, $2 \%$ incinerated, $1 \%$ landfilled and $49 \%$ were recycled [10]. Pyrolysis or gasification are processes that considerably reduce the environmental impact compared to ordinary combustion. Their implementation can enhance waste management and reduce toxic emissions, associated with the elimination of wood waste, allowing an important energy recovery [11,12]. The solid by-product of pyrolysis and gasification processes is represented by biochar, which nowadays is mainly used as a soil amendment [13-18]. Additionally, biochar has the potential of reducing net greenhouse gas (GHG) emissions by about $870 \mathrm{~kg} \mathrm{CO}_{2}$ equivalent $\left(\mathrm{CO}_{2}-\mathrm{e}\right)$ per ton dry feedstock [19] depending on the type of feedstock and preparation conditions used. From the construction point of view, biochar can be an excellent construction material because it is generally characterized by low thermal conductivity and flammability, while it is chemically stable by high fixed carbon levels [20]. It has high specific surface areas and pore volumes, and good adsorption capacity [21], which generates a good interaction with cementitious matrix. It is also known that the pores can promote water retention during the mixing stage. This water is then released as the available moisture used up for hydration reactions, promoting secondary hydration reactions and additional curing, resulting in a concrete with improved mechanical properties [22].

The use of biochar in cementitious mixtures has been shown to be beneficial since it can lead to an improvement of the physical and mechanical properties of the material [23-31]. However, since biochar used in literature comes from different raw materials and from production plants with different characteristics, there is no ideal mix design for its use, mainly due to the high variability of the intrinsic characteristics of biochar particles. The morphology, the content of pure carbon, the release of volatiles, the size and distribution of pores of biochar strongly depend on the type of biomass and the characteristics of the process of production, namely presence or not of oxygen under the stoichiometric limit (i.e. pyrolysis or gasification), maximum temperature, heating rate and pressure [32]. Moreover, biochar particles can be subjected to different pre-treatments before their addition to cementitious mixtures, such as sieving, grinding or pre-soaking. All these treatments influence the way biochar interacts with the cementitious matrix, thus leading to more or less promising results. In this work, the use of biochar from gasification of local forest wood chips (named "Borgotaro Gray" biochar in the following) has been investigated both as filler and as cement replacement in cement paste and mortar mixes.

The aim is to evaluate the optimal percentage of addition/replacement of biochar and the influence of mixture parameters (i.e. if biochar is inserted dry or pre-soaked with water in the admixture). More in detail, the experimental program has consisted of two series of tests, the first one on cement pastes, carried out at Politecnico of Torino, and the second one on cementitious mortars, carried out at University of Parma. The study was mainly focused on the mechanical characterization of the obtained cement-based composites as a first step to develop environmentally-friendly concretes.

\section{BIOCHAR: CHEMICAL AND PHYSICAL CHARACTERIZATION}

ray Borgotaro biochar was produced from virgin wood chips through gasification, by an industrial "downdraft" system in which the fuel (wood) and the gas move in the same direction, while the maximum temperature reached is about $700{ }^{\circ} \mathrm{C}$. 
The feedstock choice is related to worldwide (and local) availability of wood waste, so as to promote sustainability and circular economy. Moreover, Gray Borgotaro biochar cannot be used as a soil improver, due to the fineness of its particles, since it represents the finest waste in cogeneration energy production process. Furthermore, the choice of a feedstock biomass (the wood chips of local forests) that remains fairly homogeneous over the year, compared to other types of wastes, such as for example, municipal wastes, assures reliable experimental results.

To understand the mechanical results correctly, "Gray Borgotaro" biochar was first chemically and physically characterized, as reported in the following.

\section{Particle size distribution}

Laser granulometry was used to determine the Gray Borgotaro biochar particle size distribution through FRITSCH analysette 22 COMPACT laser on an alcoholic suspension previously dispersed under sonication for 5 minutes. The obtained particle size distribution is shown in Fig. 1. The particles ranges from some nanometers up to $40 \mu \mathrm{m}$ and $50 \%$ of them have a size less than $8 \mu \mathrm{m}$.

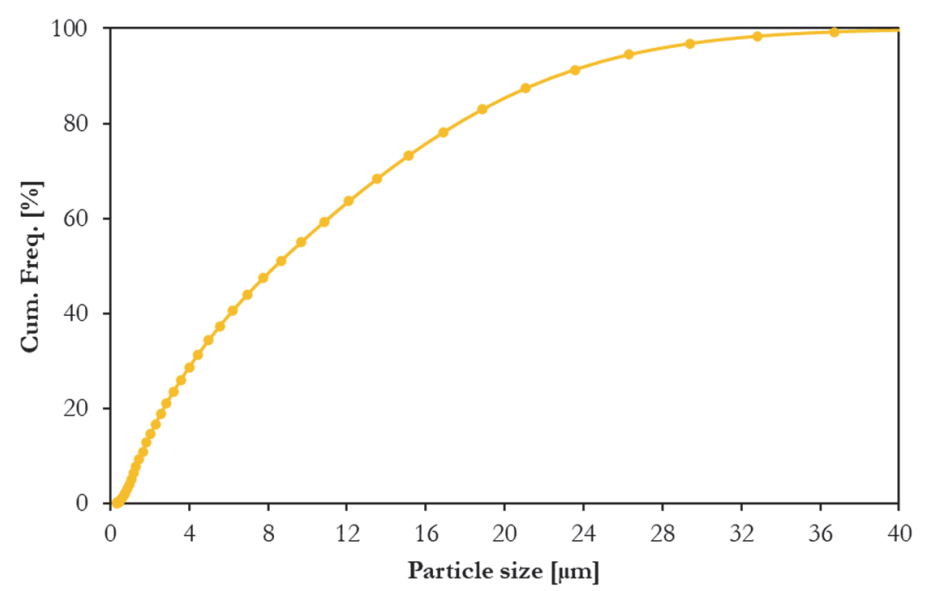

Figure 1: Gray Borgotaro biochar particle size distribution.

\section{Water retention capacity of biochar}

The method proposed by Gupta et al. [21] was used to determine the water holding capacity. First, in a continuous air flow oven at $70.3{ }^{\circ} \mathrm{C}, 30 \mathrm{~g}$ of biochar were dried for 24 hours to eliminate the humidity that could be present in the powder. Subsequently, three beakers were filled with $100 \mathrm{~g}$ of distilled water and $10 \mathrm{~g}$ of biochar (see Fig. 2). Then, the samples were sealed and left to rest for 48 hours. Finally, each solution was filtered with a vacuum pump (with cellulose filter) until there was no free water flow. The dry biochar weight was then subtracted from the soaked biochar weight, thus obtaining an absorbed water mass of $2.17 \mathrm{~g}$ of water for each gram of dry Gray Borgotaro biochar. According to Gupta and Kua [33], the retention of water by biochar makes it a potential cementitious matrix material thanks to its morphology and surface pores. Micropores and nanopores provide a site for adsorption of aqueous solutions. Furthermore, the biochar obtained at high temperature has high pore fractions capable of rapidly absorbing moisture, retaining part of the mixing water, helping in the subsequent cement hydration process [34].

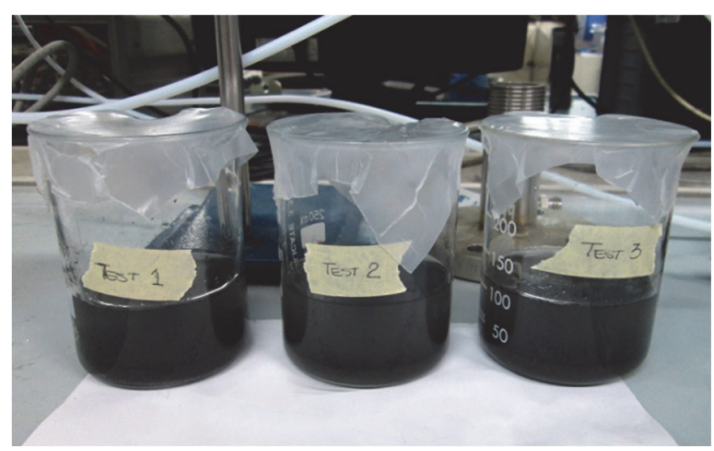

Figure 2: Water-biochar solution specimens. 


\section{Thermogravimetric analysis (TGA) of biochar}

Thermogravimetric analysis was performed using a Perkin Elmer Pyris 1 TGA. 2 mg of Gray Borgotaro biochar were used to the scope. The analysis was performed with a heating rate of $30{ }^{\circ} \mathrm{C} / \mathrm{min}$ from 30 to $700{ }^{\circ} \mathrm{C}$ under $\mathrm{N}_{2}$. Generally, the biochar thermostability depends on its production process temperature: the increase in temperature originates more stable carbon forms with a high heat resistance of the material [35]. To verify if the residual weight is due to a more stable carbon formed during the gasification process, TGA were carried out in air because the organic compounds, in contrast to the inorganic ones, lead to combustion reaction in the presence of oxygen. The thermogram in Fig. 3 shows the presence of an unburnt fraction that could be attributed to the presence of inorganic compounds or metals.

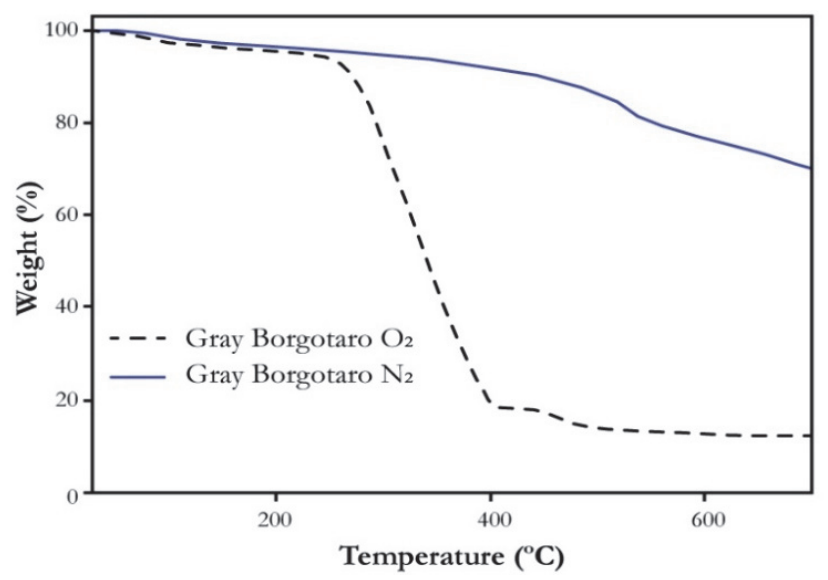

Figure 3: Thermogravimetric analysis was conducted under the flow of $\mathrm{O}_{2}$ and $\mathrm{N}_{2}$.

\section{The Potential of Hydrogen ( $\mathrm{pH}$ ) of biochar}

Gray Borgotaro biochar $\mathrm{pH}$ was determined by preparing a homogeneous aqueous suspension according to a biochar/deionized water weight ratio of 1:10 and after 90 minutes of stirring in a beaker with a magnetic stirrer. A Crison $\mathrm{pH}$ meter Basic 20 was used for this test.

The $\mathrm{pH}$ measurements have been repeated after $24 \mathrm{~h}$ and after 5 days, as reported in Tab. 1. Tested biochar samples resulted alkaline, probably due to the presence of organic functional groups, carbonates, or inorganic alkalis.

\begin{tabular}{cccc}
\hline Sample & $\mathrm{pH}$ & $\mathrm{pH} \mathrm{24h}$ & $\mathrm{pH} \mathrm{5} \mathrm{days}$ \\
Gray Borgotaro Biochar & 10.22 & 10.8 & 10.95 \\
\hline
\end{tabular}

Table 1: Biochar $\mathrm{pH}$.

\section{X-ray diffraction}

Calcite ( $\mathrm{CaCO}_{3}$, JCPDS card $\left.\mathrm{n}^{\circ} 05-0586\right)$ is the main compound, while fairchildite $\left(\mathrm{K}_{2} \mathrm{Ca}\left(\mathrm{CO}_{3}\right)_{2}\right.$, JCPDS card $\left.\mathrm{n}^{\circ} 21-1287\right)$ is a secondary phase. Finally, calcium oxide (CaO, JCPDS card $\left.n^{\circ} 37-1497\right)$, portlandite $\left(\mathrm{Ca}(\mathrm{OH}) 2\right.$, JCPDS card $\left.\mathrm{n}^{\circ} 04-0733\right)$ and potassium sulfate $\left(\mathrm{K}_{2} \mathrm{SO}_{4}\right.$, JCPDS card $\left.\mathrm{n}^{\circ} 01-70-1227\right)$ are probably present as traces. Fairchildite can be found in fused wood-ash clinker that occurs in partly burned fir and hemlock trees[36]. At room temperature, in the presence of moisture, fairchildite converts to buetschliite [37]. Known as wood-ash stone or fused wood-ash stone, buetschliite is the result from wood combustion and the fusion of mostly alkali and alkaline-earth metals [38]. It has been reported from North America and Australia in a variety of conifers and angiosperms. The resulting stone is normally an off-white colour and may also contain inclusions of charcoal. Buetschliite, calcite, portlandite and periclase $(\mathrm{MgO})$ have also been reported to form in furnace slag deposits where wood chips are burnt and for firing temperatures below $750{ }^{\circ} \mathrm{C}$ [38].

Calcium oxalate (whewellite, $\mathrm{CaC}_{2} \mathrm{O}_{4} \cdot \mathrm{H}_{2} \mathrm{O}$, or weddellite, $\mathrm{CaC}_{2} \mathrm{O}_{4} \cdot 2 \mathrm{H}_{2} \mathrm{O}$ ) is a very common salt in plants, probably as a product of photosynthesis and its pyrolysis leads to the formation of calcium carbonate [38]. Apart from calcium oxalate, many plants produce micro-crystals of calcite that develop without any involvement of fire [38]. Finally, silicon may be uncommon in trees but is abundant in straw, another biofuel [38]. XRD pattern of biochar is reported in Fig. 3. 
Counts

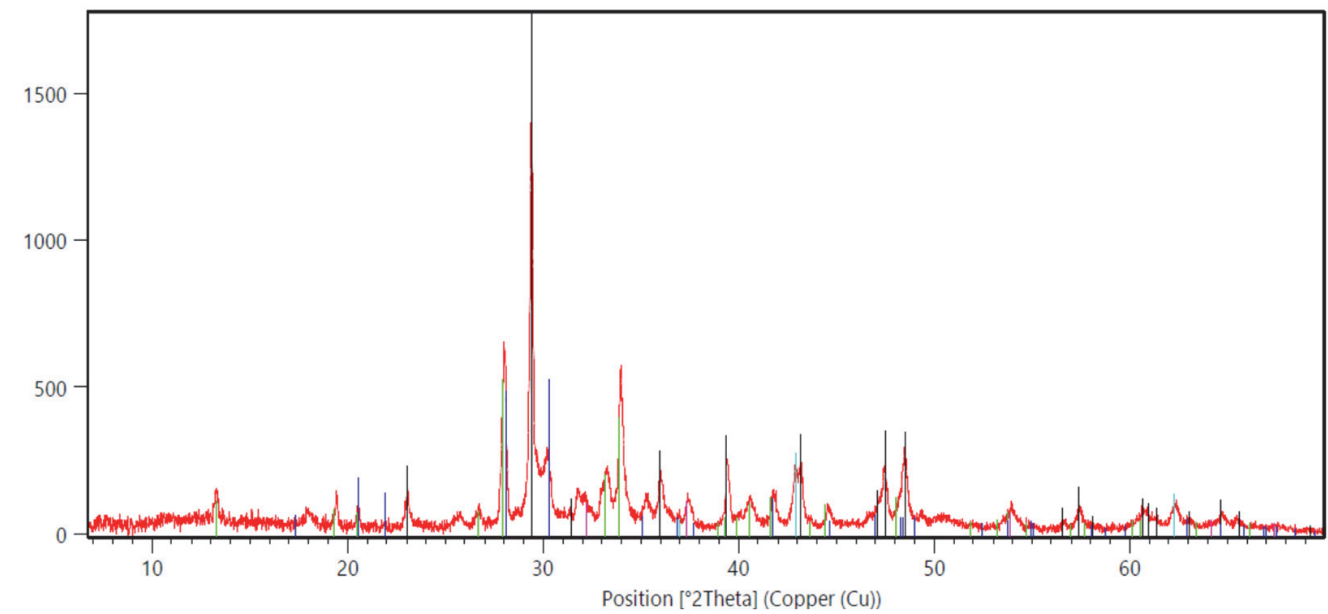

Figure 4: XRD pattern of the Gray Borgotaro biochar. (Calcite (black), fairchildite (green), calcia (fuchsia), portlandite (grey) and potassium sulfate (blue).

Mass Spectrometry with Inductively Coupled Plasma (ICP-MS)

ICP-MS (Mass Spectrometry with Inductively Coupled Plasma) is an elemental and isotopic inorganic analysis technique capable of determining and quantifying most of the elements of the periodic table in a linear dynamic range of 8 orders of magnitude (ng/L - mg/L), in addition to being able to carry out the determination of the elements in a multi-element analysis that provides the composition of the sample analysed. It can also carry out the quantification of the isotopic composition and the study of the stability of trace isotopes. Tab. 2 shows the amount of heavy metals calculated, in order to evaluate the potential environmental toxicity of the biochar used in this research.

\begin{tabular}{cccc}
\hline Metals and not metals in ICP & Unit & Value & Method \\
Arsenic $\mathrm{As}$ & $\mathrm{mg} / \mathrm{Kg}$ & 0.364 & IPC-MS-PT-IPC mass \\
Cadmium Cd & $\mathrm{mg} / \mathrm{Kg}$ & 1.94 & IPC-MS-PT-IPC mass \\
Chrome $\mathrm{Cr}$ & $\mathrm{mg} / \mathrm{Kg}$ & 6.35 & IPC-MS $12 \mathrm{~m}$-IPC mass \\
Iron $\mathrm{Fe}$ & $\mathrm{mg} / \mathrm{Kg}$ & 1310 & M05/IPC-OES-IPC optical \\
Magnesium $\mathrm{Mg}$ & $\mathrm{g} / 100 \mathrm{~g}$ & 1.52 & M05/IPC-OES-IPC optical \\
Mercury $\mathrm{Hg}$ & $\mathrm{mg} / \mathrm{Kg}$ & $<$ limit & IPC-MS-PT-IPC mass \\
Nickel $\mathrm{Ni}$ & $\mathrm{mg} / \mathrm{Kg}$ & 59 & IPC-MS-PT-IPC mass \\
Lead $\mathrm{Pb}$ & $\mathrm{mg} / \mathrm{Kg}$ & 11.3 & IPC-MS-PT-IPC mass \\
Potassium $\mathrm{K}$ & $\mathrm{g} / 100 \mathrm{~g}$ & 6.07 & M05/IPC-OES-IPC optical \\
Copper $\mathrm{Cu}$ & $\mathrm{mg} / \mathrm{Kg}$ & 57.2 & M05/IPC-OES-IPC optical \\
Sodium $\mathrm{Sa}$ & $\mathrm{g} / 100 \mathrm{~g}$ & 0.115 & M05/IPC-OES-IPC optical \\
Zinc $\mathrm{Zn}$ & $\mathrm{mg} / \mathrm{Kg}$ & 230 & M05/IPC-OES-IPC optical
\end{tabular}

Table 2: Quantity of heavy metals calculated by inductively coupled plasma mass spectrometry (ICP-MS).

Gas chromatography with mass spectrometric (GC-MS)

Another environmental concerns of biochar application in construction and building industry is its potential contamination with heavy metals (HMs) and polycyclic aromatic hydrocarbons. 
Determination of PAH content in biochar currently include gas chromatography analysis. First, $5 \mathrm{~g}$ of biochar were extracted by the acetone mixture: hexane $=1: 1$; the solvent was then evaporated by means of a rotary evaporator and the whole was weighed. The extracted fraction was then recovered with the acetone mixture: hexane $=1: 1(1-2 \mathrm{ml})$, adsorbed on a small silica column $(5 \mathrm{ml})$, recovered by washing with $5 \mathrm{ml}$ of the usual mixture and finally dried. Subsequently, a known amount of the extract $(2.8,23.6,19.6$ and $81.4 \mathrm{mg}$ respectively) was recovered with toluene $(28,236,196$ and $814 \mu$ l respectively), a quantity of diphenyl was added, used as internal standard, calculated as a function of the extract, (namely mg extracted: $\mathrm{mg}$ diphenyl = 10:1), and injected into the gas-mass instrument (GC-MS) to evaluate the possible presence of polycyclic aromatic hydrocarbons $(1 \mu \mathrm{l}$ split mode 1/20 ratio). The instrument used is a GC-MS (Agilent) equipped with a capillary column of $30 \mathrm{~m}(0.25 \mathrm{~mm}$ i.d., $0.25 \mathrm{mcm}$ f.t) connected with a $5 \mathrm{~m}$ silica pre-column (i.d $0.53 \mathrm{~mm}$ ). Data were recorded in a scan mode of $70 \mathrm{eV}(41-440 \mathrm{~m} / \mathrm{z})$. A standard mixture containing 16 common IPAs was injected under the same conditions to allow identification and quantification of polycyclic aromatic hydrocarbons possibly present in the biochar samples.

Tab. 3 shows the total content of PAH (polycyclic aromatic hydrocarbon), that are present in the analysed biochar. This is equal to $0.25 \mathrm{mg} / \mathrm{Kg}$, which represents the amount of Phenanthrene, since the content of PAH is below the detection limit (LOD: $0.050 \mathrm{mg} / \mathrm{kg}$ ) of the instrument, for all the other compound.

\begin{tabular}{cccc}
\hline Sample name & Unit & Value & Method \\
Naphthalene & $\mathrm{mg} / \mathrm{Kg}$ & $<$ LOD & GC-MS \\
Acenaphthylene & $\mathrm{mg} / \mathrm{Kg}$ & $<$ LOD & GC-MS \\
Acenaphthene & $\mathrm{mg} / \mathrm{Kg}$ & $<$ LOD & GC-MS \\
Fluorene & $\mathrm{mg} / \mathrm{Kg}$ & $<$ LOD & GC-MS \\
Phenanthrene & $\mathrm{mg} / \mathrm{Kg}$ & 0.25 & GC-MS \\
Anthracene & $\mathrm{mg} / \mathrm{Kg}$ & $<$ LOD & GC-MS \\
Fluoranthene & $\mathrm{mg} / \mathrm{Kg}$ & $<$ LOD & GC-MS \\
Pyrene & $\mathrm{mg} / \mathrm{Kg}$ & $<$ LOD & GC-MS \\
Benz(a)anthracene & $\mathrm{mg} / \mathrm{Kg}$ & $<$ LOD & GC-MS \\
Chrysene & $\mathrm{mg} / \mathrm{Kg}$ & $<$ LOD & GC-MS \\
Benzo(b)fluoranthene & $\mathrm{mg} / \mathrm{Kg}$ & $<$ LOD & GC-MS \\
Benzo(a)pyrene & $\mathrm{mg} / \mathrm{Kg}$ & $<$ LOD & GC-MS \\
Benzo(b)pyrene & $\mathrm{mg} / \mathrm{Kg}$ & $<$ LOD & GC-MS \\
\hline
\end{tabular}

Table 3: Content of PAH $(\mathrm{mg} / \mathrm{kg})$ in Gray Borgotaro biochar sample.

\section{BET analysis}

The porosity and specific area of the biochar was determined by the adsorption isotherm and desorption of nitrogen $\left(\mathrm{N}_{2}\right)$ at $77.35 \mathrm{~K}$ (liquid nitrogen temperature) by the BET method (Brunauer, Emmett and Teller) [39]. A Tristar II Krypton 3020 was used to determine nitrogen adsorption-desorption isotherms at the boiling point of liquid nitrogen.

From the nitrogen adsorption curve, it was possible to detect a high nitrogen adsorption that translates a high specific area of $28.06 \mathrm{~m}^{2} / \mathrm{g}$, in addition, the average size of the pores is $32.73 \AA$ or, $3.27 \mathrm{~nm}$, facilitating any access to adsorption.

\section{Field Emission Scanning Electron Microscopy (FE-SEM) on biochar}

The morphology of samples was observed by means of a Zeiss, FE-SEM at $20 \mathrm{kV}$. It can be observed in Fig. 5 and 6 that biochar maintains part of the biomass fibrous structure and it clearly seems to be porous. The porous structure of biochar could be derived either from the porous structure existing in raw biomass or it was formed during the gasification process. 


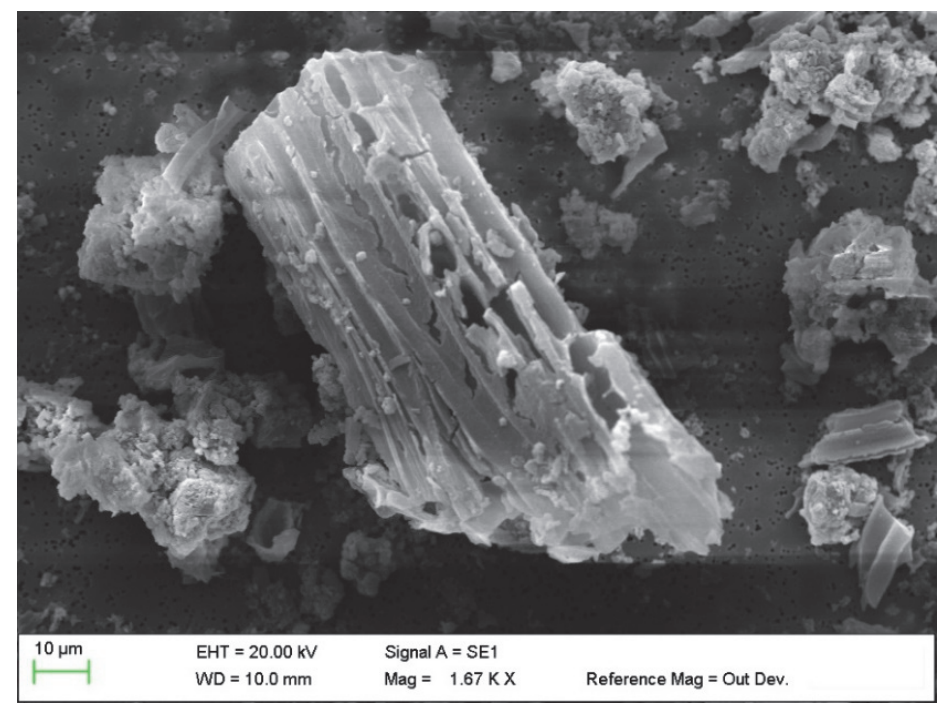

Figure 5: FESEM micrograph of Gray Borgotaro biochar, 1670× magnification.

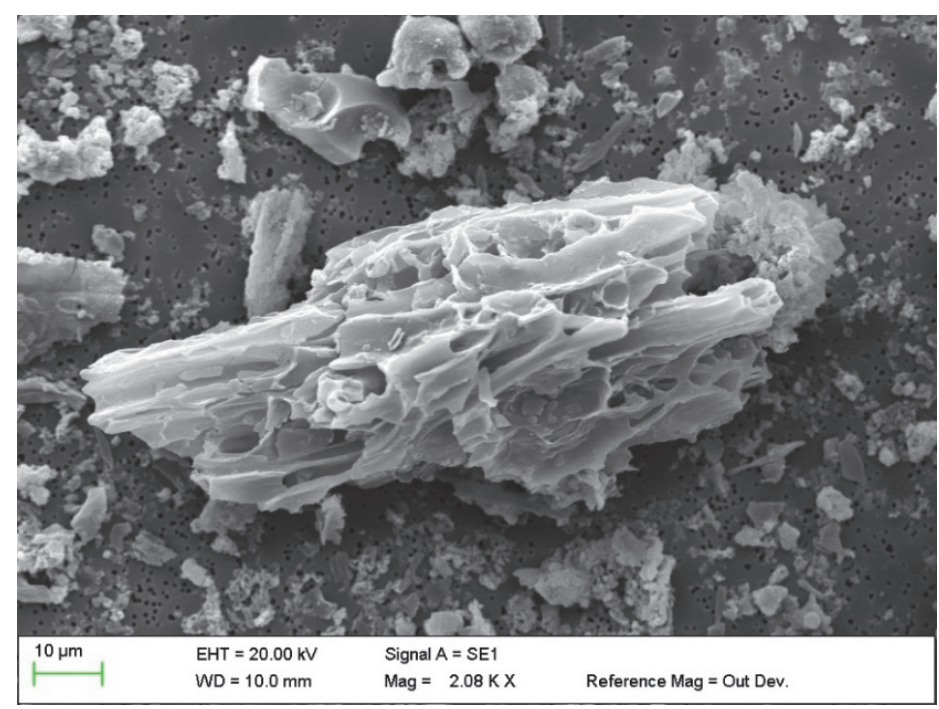

Figure 6: FESEM micrograph of Gray Borgotaro biochar, 2080× magnification.

\section{Preparation of Biochar-ADDED CEMENTItious Composites}

\section{Cement pastes}

Eleven types of cement paste specimens were made using Ordinary Portland Cement (OPC) type I 52.5R (see Tab. 4) and the experimental campaign was divided into two parts.

In the first one, the behavior of biochar as a filler in cementitious composites was analyzed. Based on the experience of previous studies carried out at Politecnico di Torino [25-27,40,41] five different percentages with respect to the weight of cement were used $(0.8 \%, 1 \%, 1.5 \%, 2 \%$, and $2.5 \%)$ with a water to cement w/c ratio equal to 0.35 and $1 \%$ of superplasticizer Dynamon SP1.

The second experimental campaign explored the use of biochar as substitute of ordinary Portland cement. Therefore, the best percentage of the previous campaign was chosen $(2 \%)$ and the mixture parameters (in water or dry) were varied. Furthermore, another batch was prepared (with biochar used both as a filler and a substitute) with the w/c ratio equal to 0.40 , considering the effective reduction of water in the mixture generated by the biochar [33], and with the optimal mixing procedure (in water). Cement pastes were cast into $20 \times 20 \times 80 \mathrm{~mm}$ prisms and then the samples were cured in water for 7 and 28 days before testing. 


\begin{tabular}{|c|c|c|c|c|c|c|}
\hline Batch & Description & Cement $[g]$ & $\mathrm{w} / \mathrm{c}$ & Water $[\mathrm{g}]$ & $\mathrm{SP} 1[\mathrm{~g}]$ & Biochar $[\mathrm{g}]$ \\
\hline OPC & Plain cement paste & 460 & 0.35 & 161 & 2.3 & - \\
\hline GBC $0.8 \%$ & Cement $+0.8 \%$ of biochar mixed in water & 460 & 0.35 & 161 & 2.3 & 3.68 \\
\hline GBC $1 \%$ & Cement $+1 \%$ of biochar mixed in water & 460 & 0.35 & 161 & 2.3 & 4.6 \\
\hline GBC $1.5 \%$ & Cement $+1.5 \%$ of biochar mixed in water & 460 & 0.35 & 161 & 2.3 & 6.9 \\
\hline GBC $2 \%$ & Cement $+2 \%$ of biochar mixed in water & 460 & 0.35 & 161 & 2.3 & 9.2 \\
\hline GBC $2.5 \%$ & Cement $+2.5 \%$ of biochar mixed in water & 460 & 0.35 & 161 & 2.3 & 11.5 \\
\hline GBC $2 \%$ _Sost & $\begin{array}{l}\text { Substitution of } 2 \% \text { of cement, } \\
\text { with biochar mixed in water }\end{array}$ & 225.4 & 0.35 & 80.5 & 2.3 & 4.6 \\
\hline GBC $2 \%$ _S_Sost & $\begin{array}{l}\text { Substitution of } 2 \% \text { of cement, } \\
\text { with biochar mixed in cement }\end{array}$ & 225.4 & 0.35 & 80.5 & 2.3 & 4.6 \\
\hline GBC $2 \% \_0.40$ & $\begin{array}{c}\text { Cement }+2 \% \text { of biochar mixed in water, } \\
\text { w/c ratio: } 0.40\end{array}$ & 230 & 0.4 & 92 & 2.3 & 4.6 \\
\hline GBC $2 \%$ 0.40_Sost & $\begin{array}{l}\text { Substitution of } 2 \% \text { of cement, } \\
\text { with biochar mixed in water, w/c ratio: } 0.40\end{array}$ & 225.4 & 0.4 & 92 & 2.3 & 4.6 \\
\hline
\end{tabular}

Table 4: Mix-design of cement paste.

\section{Mortars}

Two different mortar admixtures were prepared, both as a first step to develop green concrete. In more detail, the first type, denoted as $\mathrm{M}$ in Tab. 5, aims to simulate in scale a ready-mix concrete, while the second, denoted as N, refers to a mixture for precast concrete. The two admixtures differ for the water-cement ratio and the type of cement and superplasticizer used, while the same three different percentages of biochar addition $(0 \%, 1 \%, 2.5 \%$ by weight of cement) are considered. Based on previous studies $[29,31], 1 \%$ seems the most promising percentage, whereas $2.5 \%$ can be seen as the maximum addition that allows maintaining an adequate workability without exceeding standard doses of superplasticizer and without producing unstable mixes that start to show bleeding and segregation. In this study, higher superplasticizer dosage is used for increasing biochar addition in order to get about the same flowability for all the batches. The slump values, which were obtained immediately after the end of mixing by using scaled (1:2) version of the Abrams cone, are shown in Tab. 6, which also reports the fresh density of each batch.

Since the admixtures designed differ from standard cement mortars, a proper mixing procedure, based on "method of concrete equivalent mortar" (MBE) was applied, see [42,43] for further details. Mortars were cast into 40×40×160 mm prisms and then the samples was cured in water for 14 and 50 days before testing.

\begin{tabular}{cccccccccc}
\hline Batch & Cement & & w/c & Water & Superplasticizer & Biochar & \multicolumn{2}{c}{ Aggregates } \\
& type & {$[\mathrm{g}]$} & & {$[\mathrm{g}]$} & type & {$[\mathrm{g}]$} & {$[\mathrm{g}]$} & CEN sand [g] & $0-6.3 \mathrm{~mm}[\mathrm{~g}]$ \\
M 0\% & II A-LL 32.5R & 330 & 0.55 & 181.5 & Dynamon SX42 & 2.6 & - & 160 & 960 \\
M 1\% & II A-LL 32.5R & 330 & 0.55 & 181.5 & Dynamon SX42 & 3 & 1 & 160 & 960 \\
M 2.5\% & II A-LL 32.5R & 330 & 0.55 & 181.5 & Dynamon SX42 & 3.3 & 2.5 & 160 & 960 \\
N 0\% & I 42.5R & 400 & 0.4 & 160 & Dynamon SP1 & 3 & - & 200 & 980 \\
N 1\% & I 42.5R & 400 & 0.4 & 160 & Dynamon SP1 & 3.4 & 1 & 200 & 980 \\
N 2.5\% & I 42.5R & 400 & 0.4 & 160 & Dynamon SP1 & 3.8 & 2.5 & 200 & 980 \\
\hline
\end{tabular}

Table 5: Mix-design of cement mortars. 


\begin{tabular}{rcc}
\hline Batch & $\begin{array}{c}\text { Slump } \\
{[\mathrm{mm}]}\end{array}$ & $\begin{array}{c}\text { Fresh density } \\
{\left[\mathrm{Kg} / \mathrm{m}^{3}\right]}\end{array}$ \\
M 0\% & 257 & 2329 \\
M 1\% & 253 & 2310 \\
M 2.5\% & 244 & 2299 \\
N 0\% & 247 & 2361 \\
N 1\% & 296 & 2394 \\
N 2.5\% & 282 & 2386 \\
\hline
\end{tabular}

Table 6: Slump and fresh density of cement mortars.

\section{EXPERIMENTAL TESTING}

A 11 the experimental specimens were submitted to three-point bending test (3PBT), by following JCI-S-001-2003 standard [37]. A U-shaped cut (6 $\mathrm{mm}$ deep for cement pastes and double for mortars) was made in the middle of the samples. Cement pastes were tested over a net span $S$ of $70 \mathrm{~mm}$ by means of a Zwick Z050 Universal Test Machine, while for mortars the net span $S$ was equal $120 \mathrm{~mm}$ and an Instron 8862 Universal Test Machine was used. The tests were performed under Crack Mouth Opening Displacement (CMOD) control by using a clip-on gauge in order to evaluate both flexural strength $\sigma_{f}$ and fracture energy $G_{f}$. Flexural strength $\sigma_{f}$ was determined as follows:

$$
\sigma_{f}=P_{\max } \frac{3 S}{2 b b^{2}}
$$

where $P_{\max }$ represents the peak load of the load $(P)$ - CMOD curve, while $b$ and $b$ are the width and net depth of the midcross section, respectively.

Fracture energy $G_{f}$ was evaluated by using the equation proposed in the JCI-S-001 -2003 standard [37].

$$
G_{f}=\frac{0.75 W_{0}+W_{1}}{A_{\text {lig }}}
$$

where $A_{\text {lig }}$ is the area of the broken ligament $(b \times h), W_{0}$ represents the area below the load $(P)$ - CMOD curve and $W_{1}$ is related to the work done by deadweight of specimen and loading equipment.

In order to better analyze the cracking process for biochar-added cementitious composites, FESEM observations were performed on cement pastes on some specimens previously subjected to three-point bending test, while for mortars the Digital Image Correlation (DIC) technique was adopted by using a NIKON D750 camera during the testing and then by means of software Ncorr to process the acquired photos.

On mortars, compression tests were performed too, in accordance to Standard EN 196-1:2016 [44], on the two halves of the broken prisms, previously subjected to three-point bending test.

\section{RESULTS AND DISCUSSION}

\section{Cement pastes}

Flexural strength and fracture energy are obtained, as previously explained, from CMOD curves, which are reported as an example in Fig. 7 for cement paste specimens at 7 days. The flexural strength and fracture energy of each set are reported in Tab. 7. Each set is composed of four specimens and the results correspond to the mean values \pm standard deviation. 
Fig. 8 and 9 show respectively the results in terms of flexural strength and fracture energy of cementitious composites with biochar used as a filler, both at 7 and 28 days. The results in terms of flexural strength and fracture energy for the different cases where $2 \%$ biochar was used (GBC 2\%_Sost, GBC 2\%_S, GBC 2\%_S_Sost, GBC 2\%_0.40, GBC 2\%_0.40_Sost) are shown in Fig. 10 and 11, respectively. It is worth noticing that in this case, the tests to determine flexural strength and fracture energy after 28 days could not be performed for technical problems due to the global pandemic caused by coronavirus (COVID-19).

It can be recognized that the batches in which GBC was used as a filler in small amounts (GBC $0.8 \%$ ) show a decrease of flexural strength compared to the plain cementitious paste, both at 7 and 28 days. For 1 wt. $\%$ and 1.5 wt. $\%$ it can be noted that the values differ between 7 and 28 days: in the case of 7 days curing there is a slight decrease in flexural strength, while at 28 days a significant increase compared to the reference samples is observed $(+7 \%$ and $+10 \%$ respectively).

The addition of $2 \mathrm{wt.} \%$ and $2.5 \mathrm{wt} . \%$ of cement leads to an increase of the flexural strength at 7 days by more than $15 \%$ and almost $10 \%$ respectively, while the results at 28 days are quite different between the two batches. In fact, GBC $2 \%$ roughly has the same flexural strength as OPC ones, while GBC 2.5\% shows a significant decrease (more than 20\%), probably because of a not optimal dispersion of biochar in the cementitious matrix.

Regarding fracture energy, it is clear that the results at 7 and 28 days do not follow the same trend of the flexural strength: at 7 days the results give a linear growth trend, the higher the percentage of particles of biochar, the higher the values of fracture energy (the composition with $2.5 \mathrm{wt} . \%$ of biochar shows an increase around 40\% compared with OPC sample). On the other hand, the 28-day results are difficult to interpret, because of fluctuations in values that can perhaps only be explained by the ability of biochar to interact with the hydration of the samples during the curing phase.

\begin{tabular}{lcccc}
\hline Batch & \multicolumn{2}{c}{ Flexural strength $\sigma_{f}[\mathrm{MPa}]$} & Fracture energy $G_{f}$ & {$[\mathrm{~N} / \mathrm{mm}]$} \\
& 7 days & 28 days & 7 days & 28 days \\
OPC & $1.82 \pm 0.17$ & $2.10 \pm 0.22$ & $0.013 \pm 0.007$ & $0.019 \pm 0.003$ \\
GBC 0.8\% & $1.36 \pm 0.67$ & $1.78 \pm 0.39$ & $0.011 \pm 0.010$ & $0.053 \pm 0.040$ \\
GBC 1\% & $1.70 \pm 0.31$ & $2.25 \pm 0.77$ & $0.027 \pm 0.006$ & $0.030 \pm 0.020$ \\
GBC 1.5\% & $1.44 \pm 0.43$ & $2.31 \pm 0.59$ & $0.033 \pm 0.011$ & $0.013 \pm 0.003$ \\
GBC 2\% & $2.10 \pm 0.52$ & $2.16 \pm 0.92$ & $0.033 \pm 0.005$ & $0.033 \pm 0.011$ \\
GBC 2.5\% & $1.98 \pm 0.91$ & $1.64 \pm 0.65$ & $0.037 \pm 0.009$ & $0.027 \pm 0.006$ \\
GBC 2\%_Sost & $1.29 \pm 0.06$ & - & $0.027 \pm 0.017$ & - \\
GBC 2\%_S & $1.11 \pm 0.13$ & - & $0.021 \pm 0.04$ & - \\
GBC 2\%_S_Sost & $1.11 \pm 0.85$ & - & $0.014 \pm 0.003$ & - \\
GBC 2\%_0.40 & $2.14 \pm 0.48$ & - & $0.026 \pm 0.007$ & - \\
GBC 2\% 0.40_Sost & $1.63 \pm 0.33$ & - & $0.018 \pm 0.003$ & - \\
\hline
\end{tabular}

Table 7: Mechanical properties of the cement paste batches.
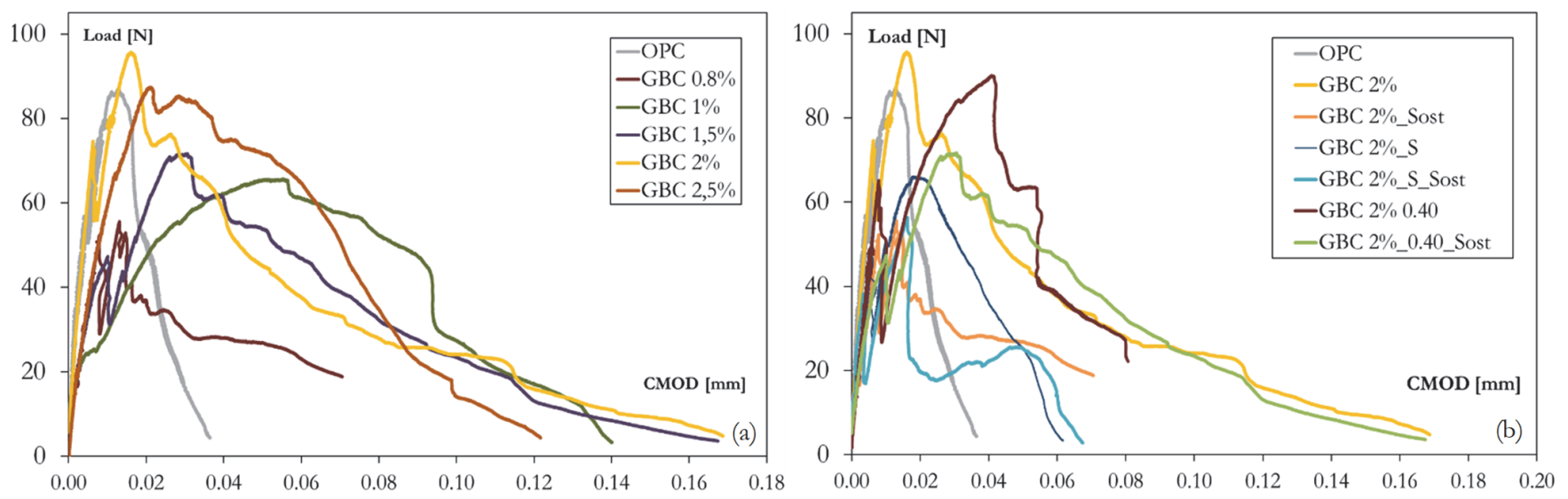

Figure 7: Load - CMOD curve as obtained from 3PBT at 7 days for the specimens from $0.8 \%$ to $2.5 \%$ (a) and all $2 \%$ specimen types. 


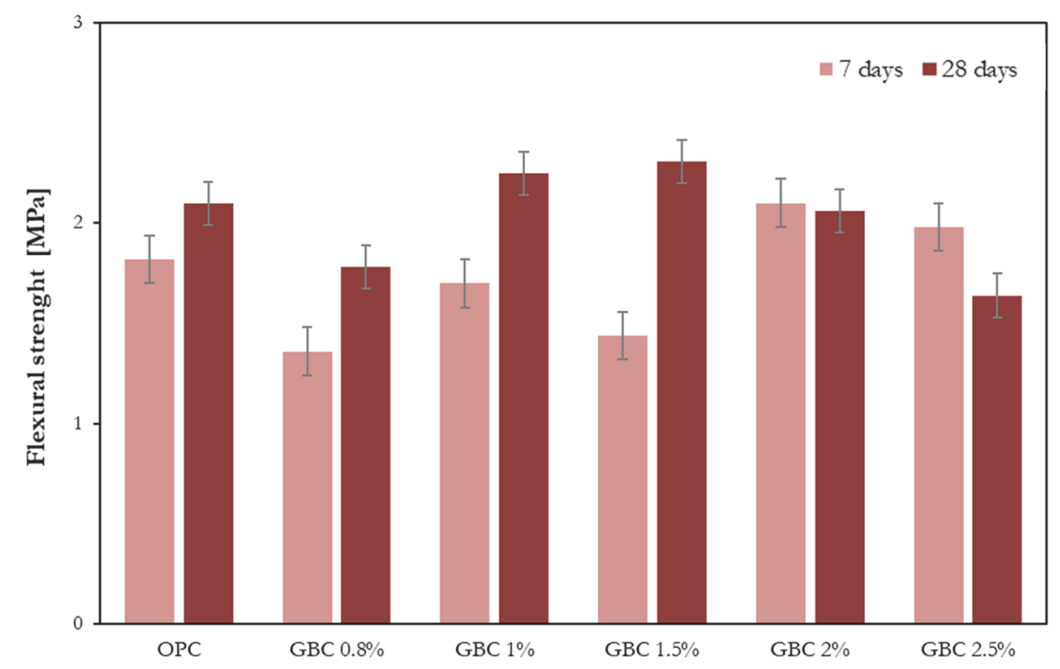

Figure 8: Flexural strength [MPa] - Average value for each batch at 7 and 28 days.

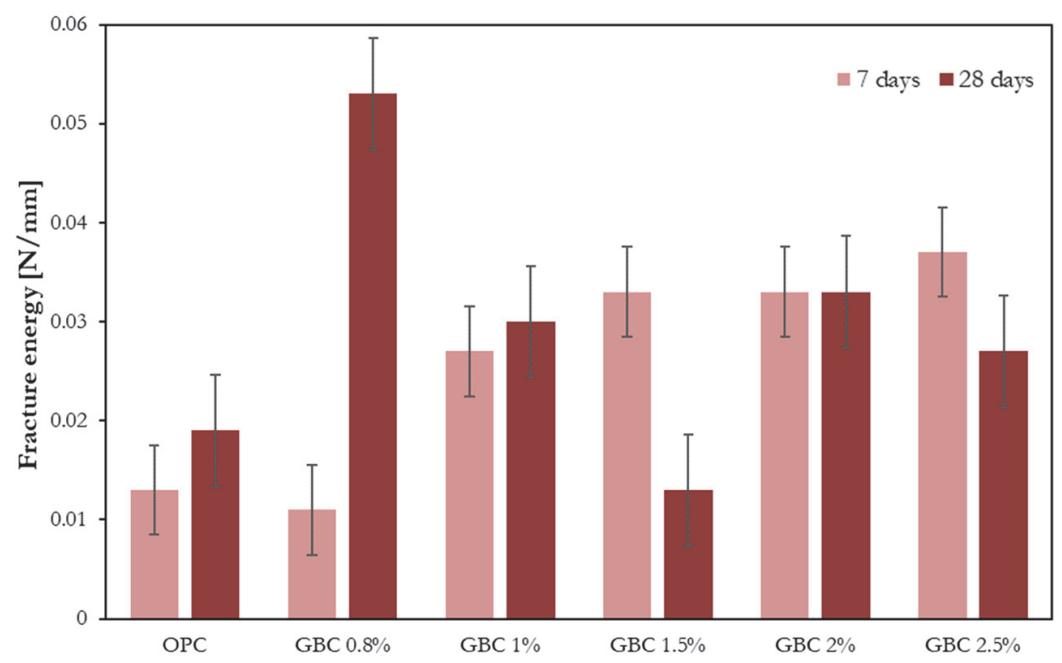

Figure 9: Fracture energy [N/mm] - Average value for each batch at 7 and 28 days.

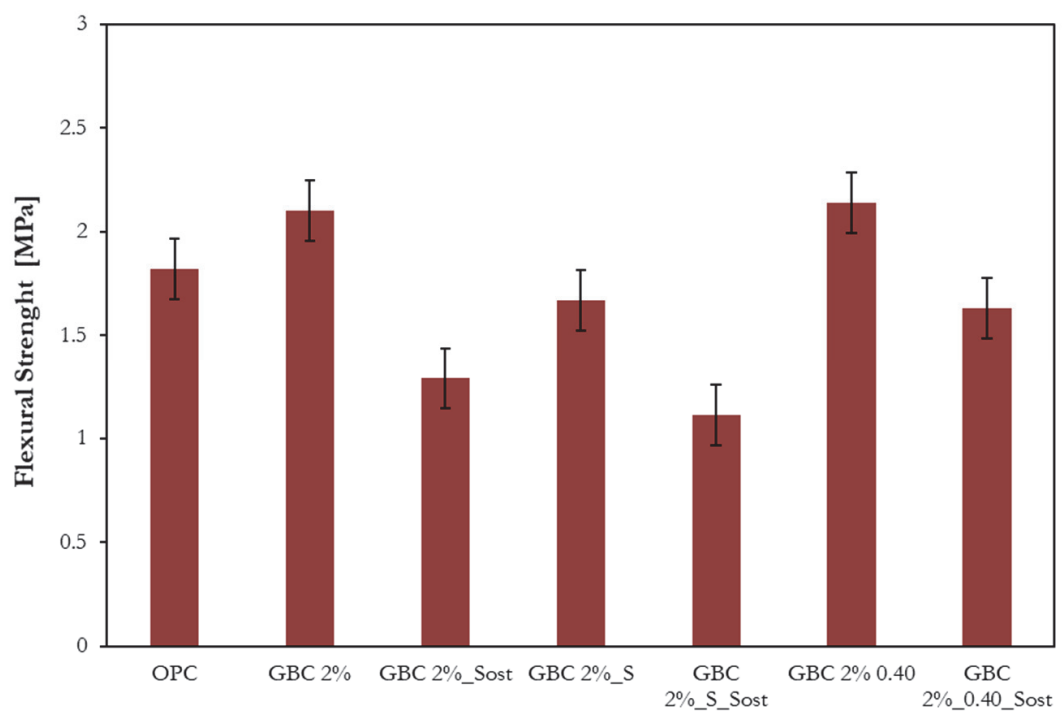

Figure 10: Flexural strength [MPa] - Average value for each batch, 7 days. 


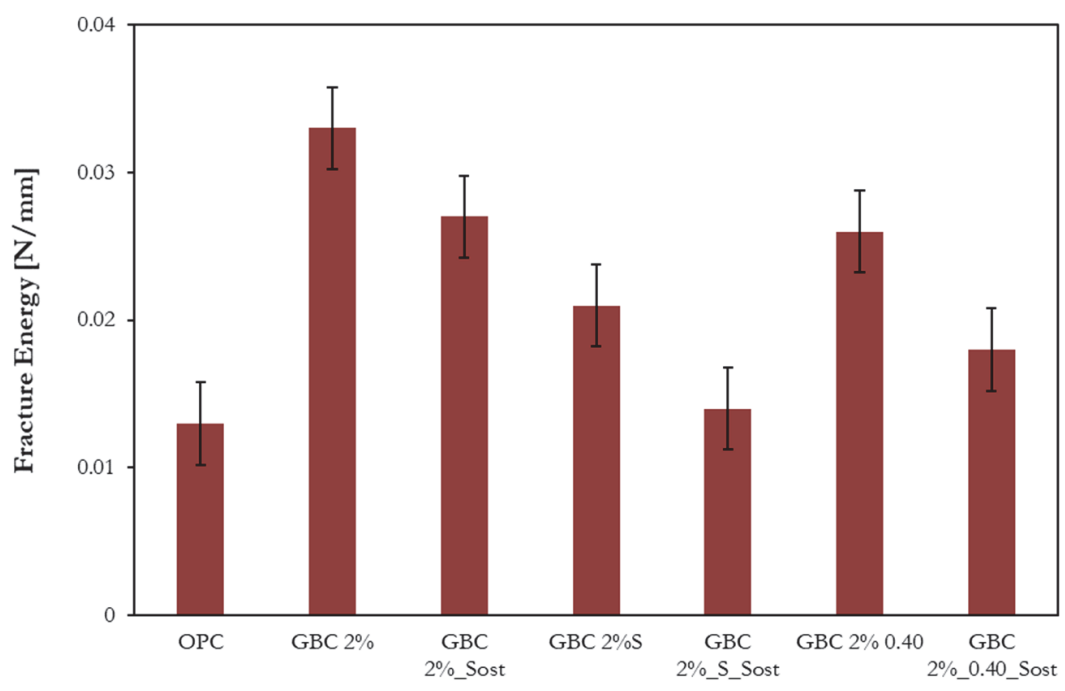

Figure 11: Fracture energy [N/mm] - Average value for each batch, 7 days.

Analyzing the results reported so far, it seems clear that the percentage of $2 \mathrm{wt} . \%$ of Gray Borgotaro biochar is the most suitable to guarantee strength and toughness, both at 7 and at 28 days, without significant fluctuation of values related to curing step. Therefore, the batches with the biochar replacing Ordinary Portland Cement were made using the aforementioned $2 \mathrm{wt.} \%$ content. In these specimens, two different mixing procedures were used (GBC 2\%_S_Sost: dry mixture, biochar mixed with cement, GBC 2\%_Sost: biochar mixed in water) and finally, choosing the mixing procedure with the best results, a final batch was cast with a w/c ratio of 0.40 (GBC 2\% 0.40_Sost).

In Fig. 10 and 11 the results of flexural strength and fracture energy at 7 days are reported for all the batches made with 2 wt. \% of "Gray Borgotaro" biochar. As for flexural strength, it is generally possible to observe that there is a slight reduction in the mechanical performance when the biochar substitutes Ordinary Portland Cement, even if a higher w/c ratio is used. Furthermore, the dry mixing typology is not a favorable solution: both in the case of biochar used as filler (GBC2\% _S) and in the case of biochar used as a substitute (GBC2\% _S_SOST), a decrease in strength is observed by almost 10\% and 40\% respectively. On the contrary, when increasing the water to cement ratio and using $2 \mathrm{wt} . \%$ of biochar as a filler (GBC2\% _.40), a mix design favorable to the preparation of composites with improved mechanical properties is obtained. This result is probably due to the water retention ability of biochar.This is also confirmed by the analysis of data relating to fracture energy (which is doubled compared to that recorded for the reference samples). It is noted that $2 \mathrm{wt} . \%$ addition of biochar used as a filler with a w/c ratio of $0.35(\mathrm{GBC} 2 \%)$ is the optimal mix design for composites providing improved (more than 150\%) mechanical properties with respect to OPC samples.

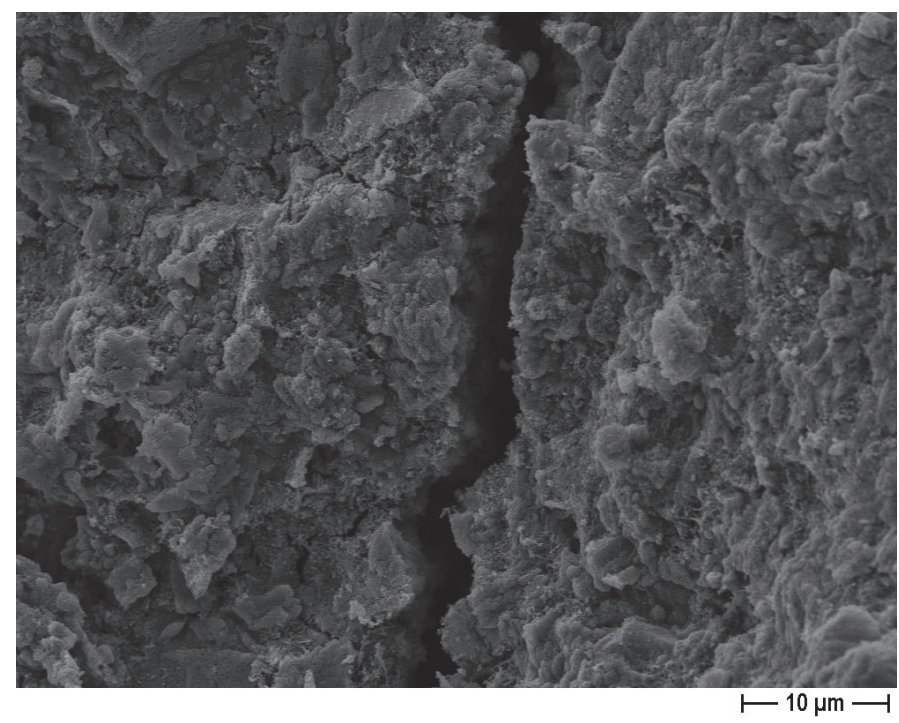

Figure 12: FESEM micrograph of GBC2\%_SOST sample, 2000× magnification. 


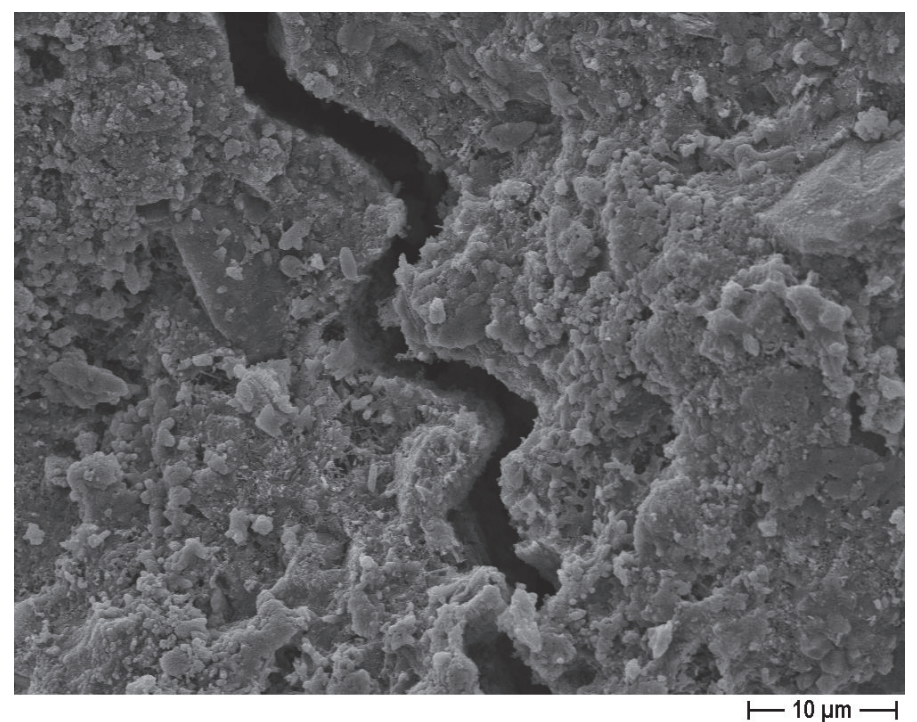

Figure 13: FESEM micrograph of GBC2\%_SOST sample, 2000× magnification.

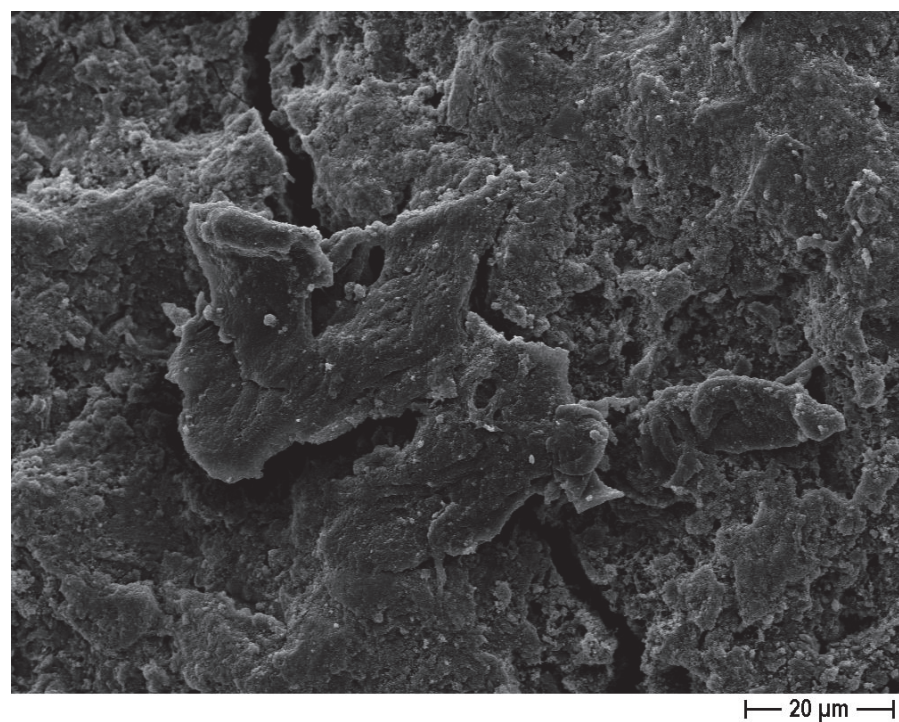

Figure 14: FESEM micrograph of GBC2\%_SOST sample, 1000× magnification.

Finally, a cementitious matrix with porous zones probably due to the fairly high water to cement ratio (0.4) used to manufacture the specimens was revealed in the FESEM images of the GBC2\% _SOST sample (Fig. 12). This effect could explain the decrease of almost $30 \%$ of the flexural strength observed with respect to the reference cement paste (OPC). In addition, the presence of biochar grains is observed in the compounds that lead to the deviation of the cracks (Figs. 13, 14). This also explains the fracture energy increase of the GBC2\%_SOST sample compared to the OPC samples $(0.027 \mathrm{~N} / \mathrm{mm}$ and $0.013 \mathrm{~N} / \mathrm{mm}$, respectively).

\section{Mortars}

The results of three-point bending tests in terms of mean values of flexural strength and fracture energy together with corresponding standard deviations are reported in Tab. 8 for each batch (composed of three specimens) for 14 and 50 days of curing. The same table also shows the results of compressive tests.

Flexural strength and fracture energy are obtained, as previously explained, from P-CMOD curves, which are reported as an example in Fig. 15 for mortar type $\mathrm{M}$ at 14 days. 


\begin{tabular}{lcccccc}
\hline Batch & \multicolumn{2}{c}{ Flexural Strength [MPa } & \multicolumn{2}{c}{ Fracture Energy $[\mathrm{N} / \mathrm{mm}]$} & \multicolumn{2}{c}{ Compressive Strength [MPa] } \\
& 14 days & 50 days & 14 days & 50 days & 14 days & 50 days \\
M $\%$ & $4.21 \pm 0.33$ & $5.37 \pm 0.26$ & $0.078 \pm 0.005$ & $0.089 \pm 0.003$ & $38.68 \pm 0.68$ & $47.51 \pm 1.59$ \\
M 1\% & $4.20 \pm 0.35$ & $5.05 \pm 0.54$ & $0.068 \pm 0.009$ & $0.082 \pm 0.005$ & $38.55 \pm 0.80$ & $49.82 \pm 1.00$ \\
M 2.5\% & $4.90 \pm 0.39$ & $5.37 \pm 0.49$ & $0.091 \pm 0.010$ & $0.091 \pm 0.005$ & $38.15 \pm 0.85$ & $48.16 \pm 0.69$ \\
N $\% \%$ & $6.62 \pm 0.49$ & $6.62 \pm 0.15$ & $0.115 \pm 0.012$ & $0.098 \pm 0.006$ & $86.82 \pm 1.44$ & $90.37 \pm 3.83$ \\
N 1\% & $7.04 \pm 0.80$ & $7.2 \pm 0.12$ & $0.111 \pm 0.007$ & $0.109 \pm 0.015$ & $86.36 \pm 2.58$ & $93.82 \pm 3.07$ \\
N 2.5\% & $6.53 \pm 0.24$ & $7.15 \pm 0.30$ & $0.118 \pm 0.007$ & $0.125 \pm 0.029$ & $83.01 \pm 1.01$ & $83.06 \pm 4.38$ \\
\hline
\end{tabular}

Table 8: Mechanical properties of cement mortars.
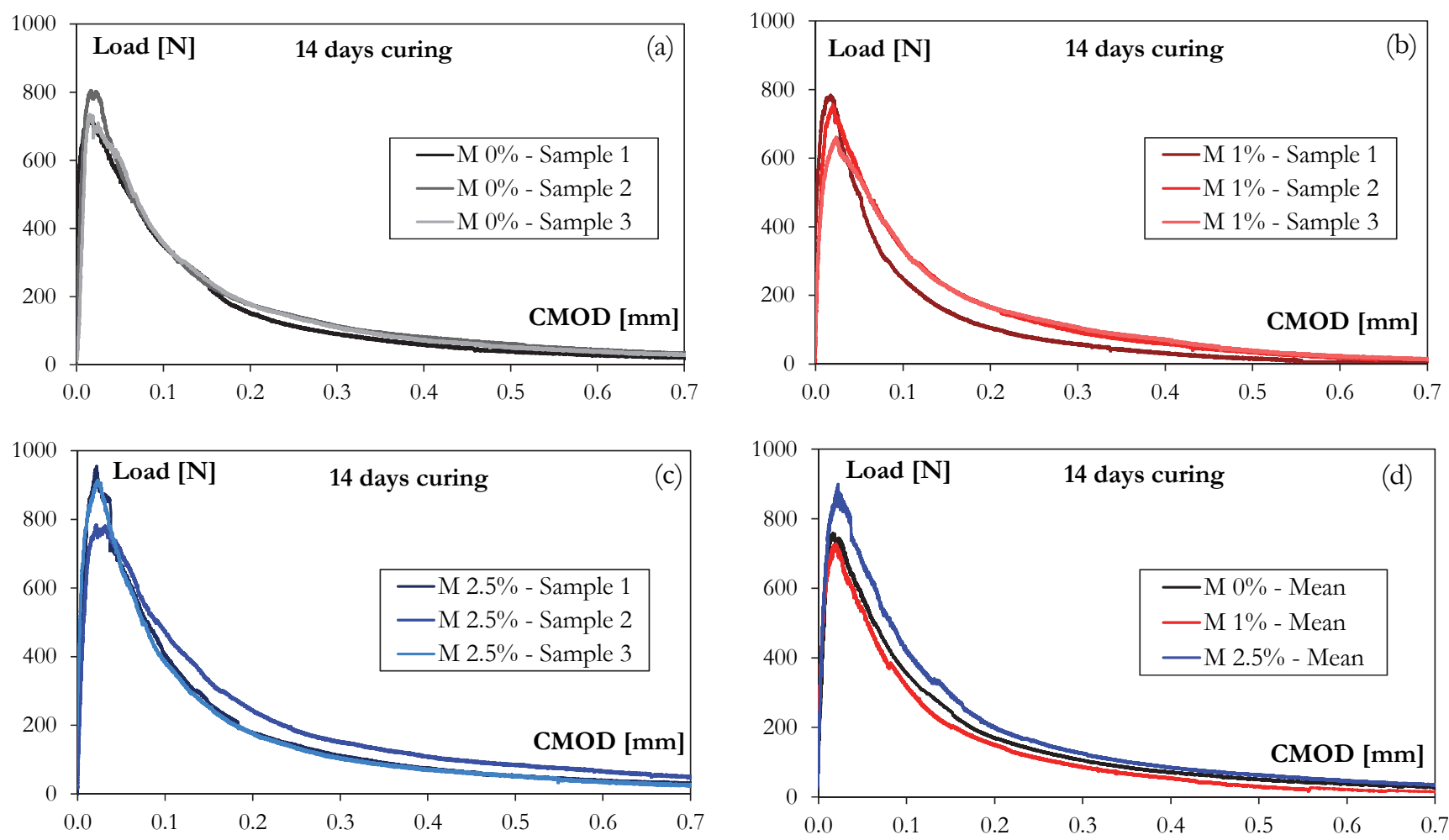

Figure 15: Load P-CMOD curve as obtained from 3PBT at 14 days for: (a) M 0\% (plain batch); (b) M 1\%; (c) M 2.5\% and (d) comparison between the mean values of the three batches.

Biochar addition of $2.5 \%$ by weight of cement leads to a general increase of both flexural strength and fracture energy for mortar type M, especially at 14 days curing, as shown in Fig. 16a and Fig. 17a. By comparing the results of flexural strength and toughness of all batches of mortar type $\mathrm{M}$, it can be seen that even if their values tend to increase, as expected, with curing age, this increment is lower as biochar percentage increases. As a matter of facts, biochar particles can act as an accelerator that produces beneficial effects on early age development of mechanical properties, as outlined in the literature [21]. As regards compressive strength, the addition of biochar does not particularly influence the results, as shown in Fig. 18a-b. Therefore, it seems that for mortar type $\mathrm{M}$ the higher percentage of biochar considered $(2.5 \%)$ is the most suitable, since it increases flexural strength and toughness, without diminishing compressive strength. These results suggest considering also different percentages (and in particular higher) of biochar for future research. However, it is worth noticing 
that $2.5 \%$ is chosen as maximum percentage in this work, since higher biochar additions require, in order to obtain good flowability, a considerable increase of water (or superplasticizer), while increasing the tendency for segregation.

When considering flexural strength of mortar type $\mathrm{N}$, the addition of $1 \%$ of Gray Borgotaro biochar provides an increase of the mean values, while for $2.5 \%$ only the results at 50 days are improved, as reported in Fig. 16b. The addition of $2.5 \%$ seems the most promising in terms of toughness for mortar type $\mathrm{N}$, though the role of biochar on fracture energy is a little bit difficult to interpret, since the results at 14 and 50 days curing follow a dissimilar trend, as shown in Fig. 17a-b. This could be explained by considering the high scatters that were registered for control batch $(\mathrm{N} 0 \%$ ) at 14 days (resulting in an

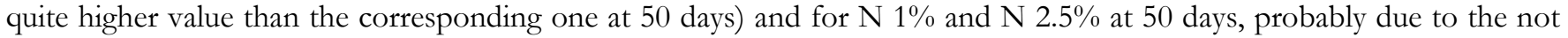
homogenous dispersion of biochar in the cementitious matrix. As regards compressive strength, the addition of $1 \%$ of biochar leads to comparable results to control, while a reduction is observed for $2.5 \%$, especially at 50 days curing, see Fig. 18b. Therefore, by analyzing the values of strength and toughness reported for mortar type $\mathrm{N}$, it is not so clear if the lower or higher percentage of addition of biochar are more suitable; therefore, future research aimed at considering a wider range of percentages (between $0 \%$ and $2.5 \%$ ) is needed.
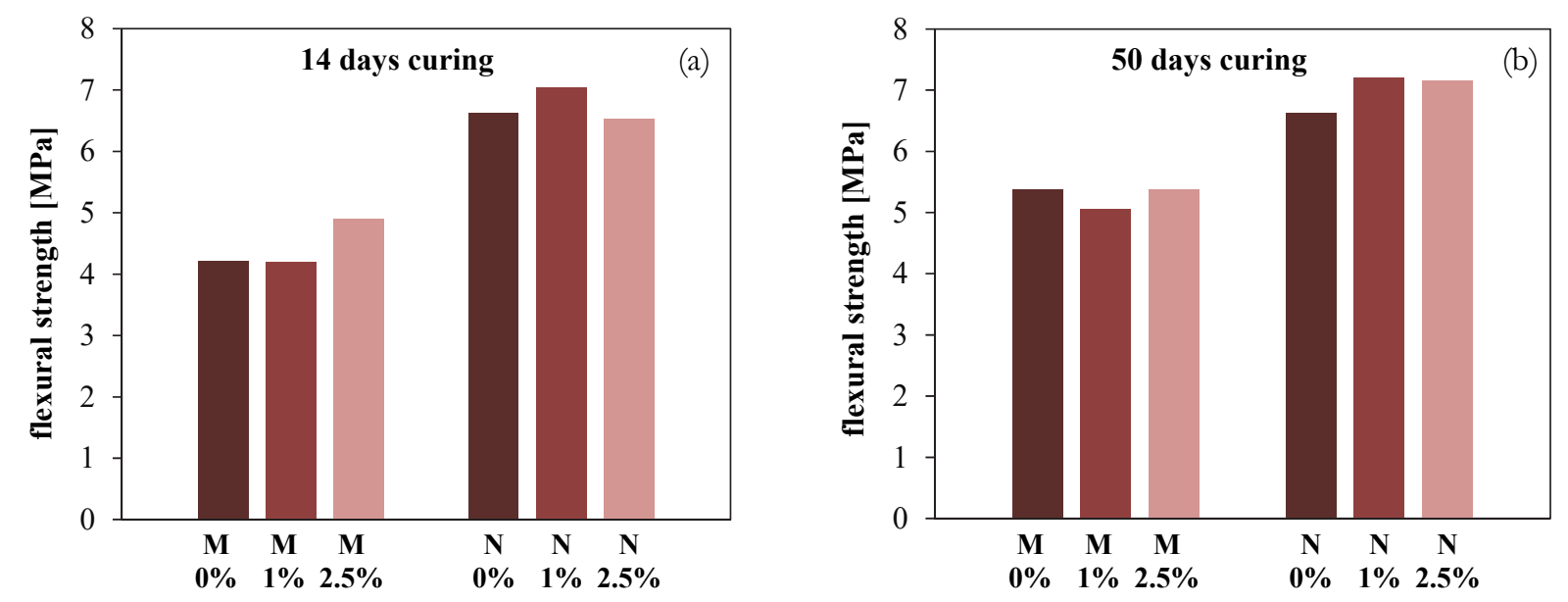

Figure 16: Flexural strength [MPa] - Average value for each batch at: (a) 14 days and (b) 50 days.
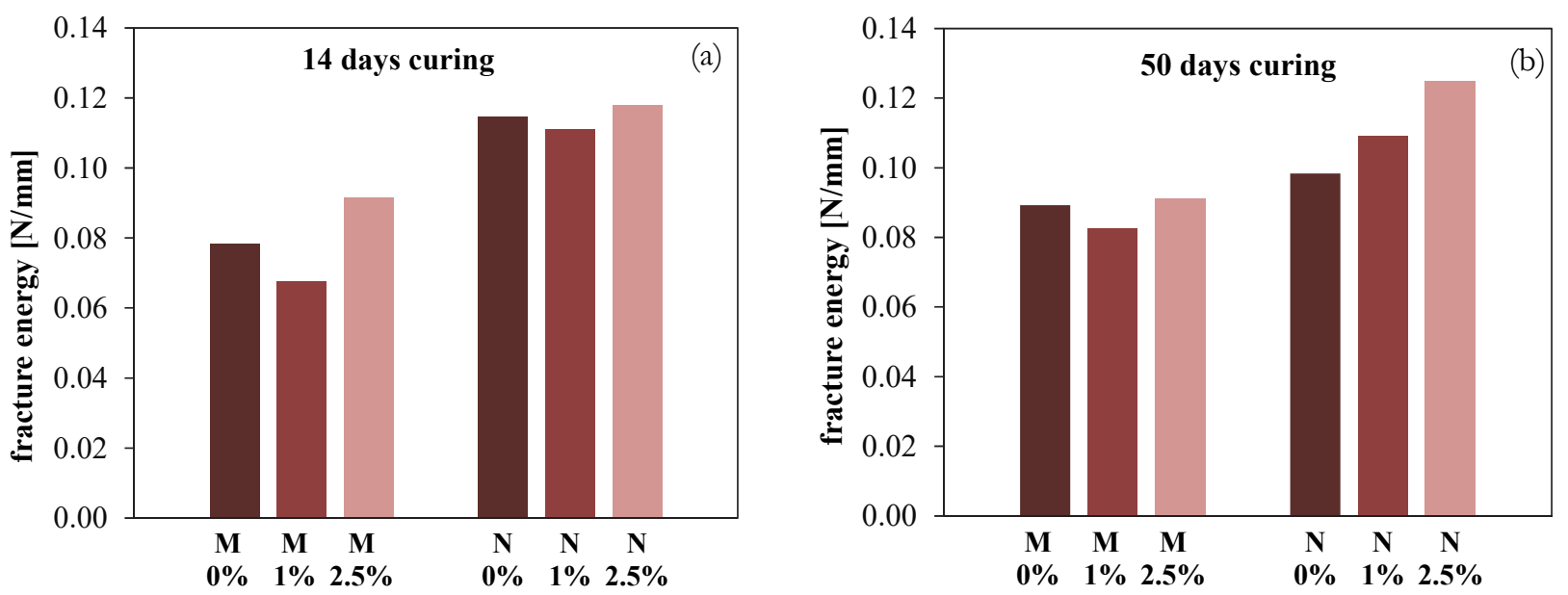

Figure 17: Fracture energy [N/mm] - Average value for each batch at: (a) 14 days and (b) 50 days.

By comparing the results obtained for mortar type $\mathrm{M}$ and $\mathrm{N}$, it seems that addition of biochar provides greater benefits for higher w/c ratio, as also seen for the cement pastes investigated in this work. This outcome is probably linked to the fine grain size and to the high absorption capacity of biochar particles that tend to compact cementitious materials; however, this densification effect is lost for mixes already compact, as characterized by low water-cement ratio, as suggested in [31]. In addition, no acceleration on the development of mechanical properties is registered for both cement pastes and mortar 
type $\mathrm{N}$, suggesting that acceleration effect of biochar reported for mortar type $\mathrm{M}$ could be linked to its interaction with limestone cement.

Moreover, as suggested by the results of cement pastes, the mixing procedure adopted in this work for mortars is not probably the most promising, since biochar was mixed with cement, while it was not pre-soaked in water, as instead it was done for cement pastes. Hence, even if satisfactory results are obtained for mortars in terms of strength and toughness, mechanical properties would be probably further enhanced by the addition of biochar thorough an optimal mixing procedure.
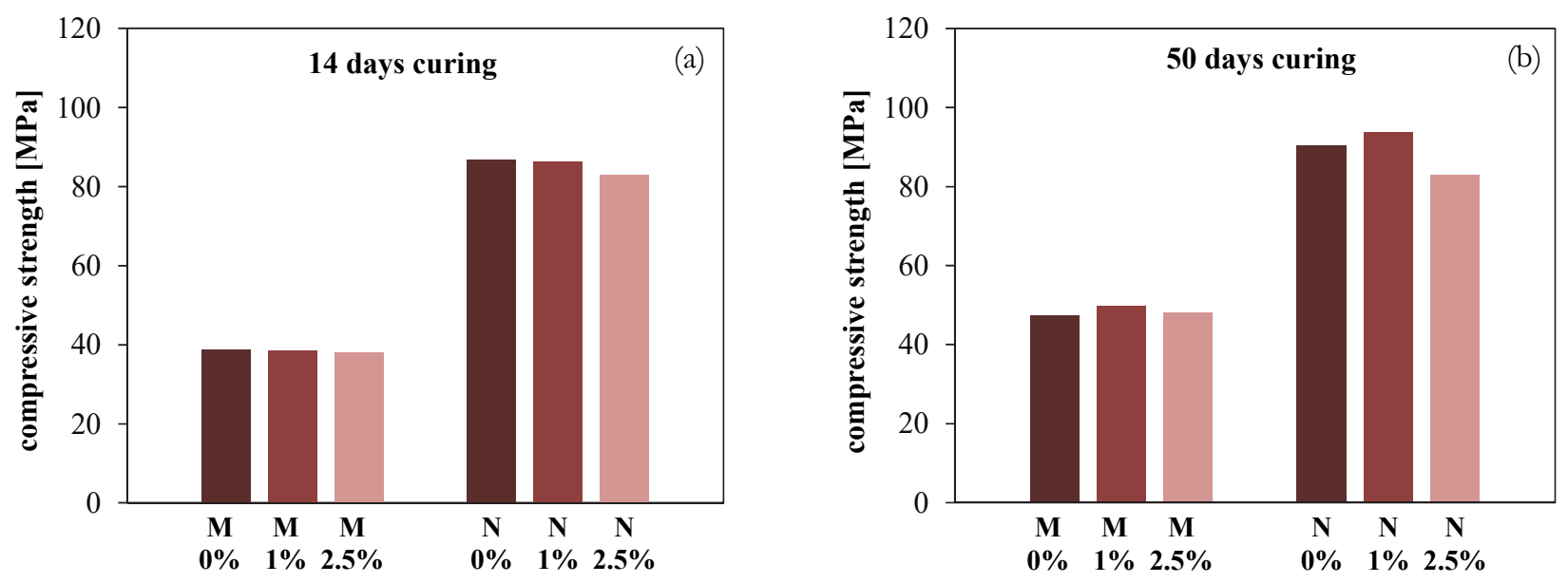

Figure 18: Compressive strength [MPa] - Average value for each batch at: (a) 14 days and (b) 50 days.

By applying Digital Image Correlation (DIC) the displacement field and the evolution of crack path can be detailed analyzed. The elaboration of vertical displacement enables to obtain the load $P$ - midspan deflection $\delta$ curve for each specimen. For sake of brevity, the mean responses for the batches of mortar type M after 14 and 50 days of curing are reported in Fig. 19, together with the corresponding mean values of fracture energy $G_{f}$. In this case, fracture energy $G_{f}$ is computed for each specimen from the load $P$ - midspan deflection $\delta$ curve, according to [45], and then averaged. As can be seen, the obtained results are in agreement with those deduced from the corresponding load-CMOD curves according to JCI-S-001 -2003 [46], and reported in Tab. 8.
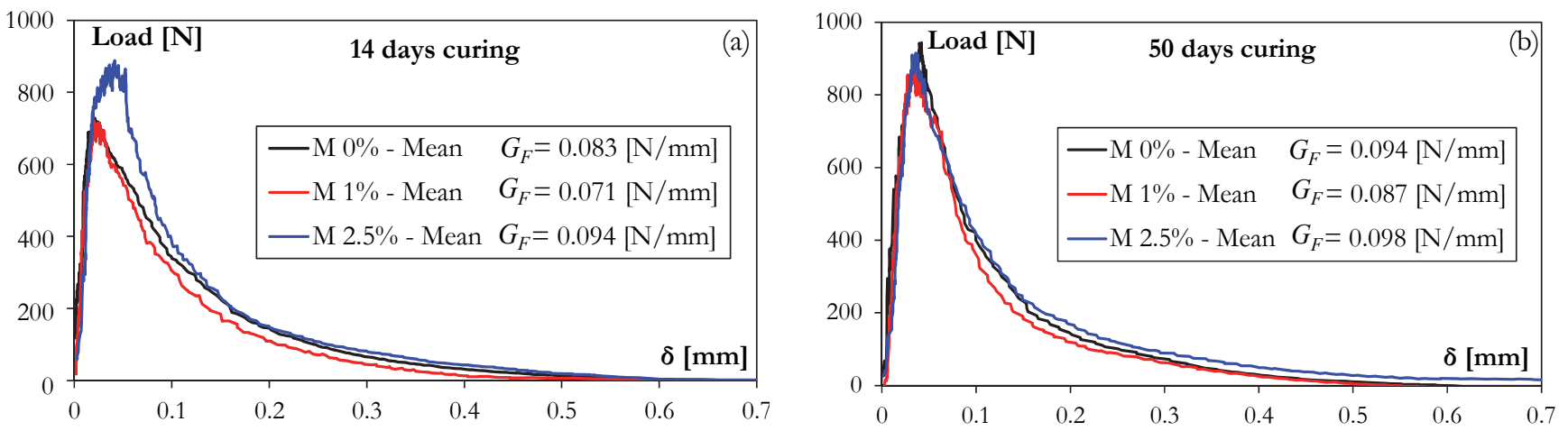

Figure 19: Average values of load $P$ - midspan deflection $\delta$ curves as obtained from DIC data elaboration for mortar type M at: (a) 14 days and (b) 50 days.

The tortuosity of crack path can be evaluated by considering the horizontal strain $\varepsilon_{x}$ field deduced from DIC data elaboration, which is reported in Fig. 20, as an example, for one sample of each batch of mortar type $\mathrm{N}$ after 50 days of curing. The development of strain values in the post-peak stage assumes the same trend for all the specimens analyzed, characterized by three different percentages of biochar addition; hence, it can be stated that the role of biochar on the development of crack path cannot be seen clearly. 


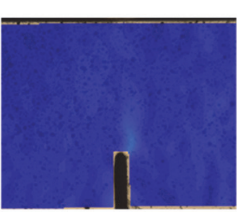

$100 \%$ peak load

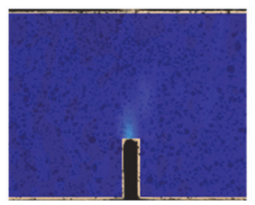

$100 \%$ peak load

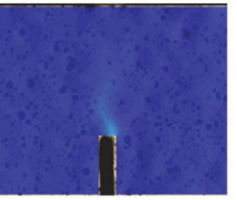

$100 \%$ peak load
$75 \%$ peak load
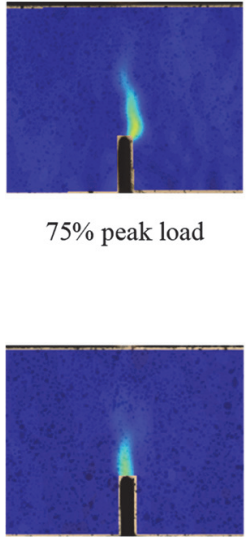

$75 \%$ peak load

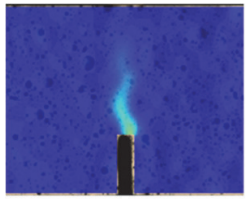

$75 \%$ peak load

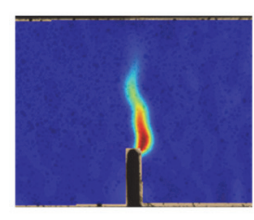

$50 \%$ peak load

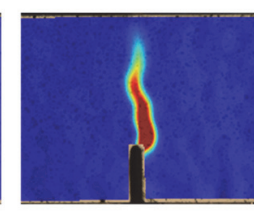

$25 \%$ peak load

N 1\% - Sample 1

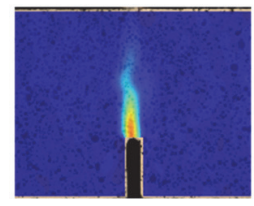

$50 \%$ peak load

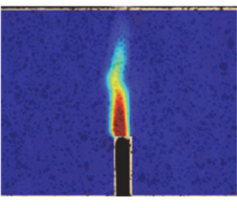

$25 \%$ peak load
N 2.5\% - Sample 1

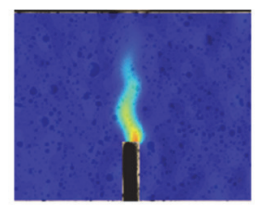

$50 \%$ peak load

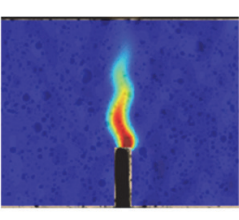

$25 \%$ peak load

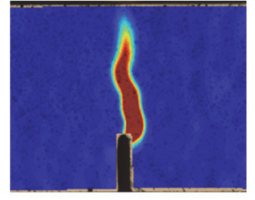

$10 \%$ peak load

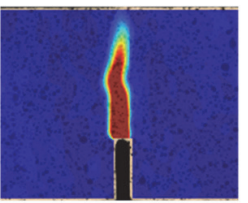

$10 \%$ peak load

(a)

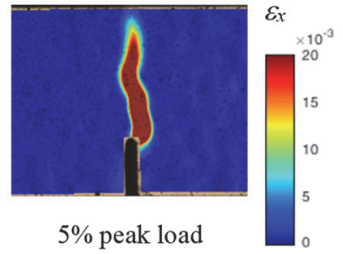

(b)

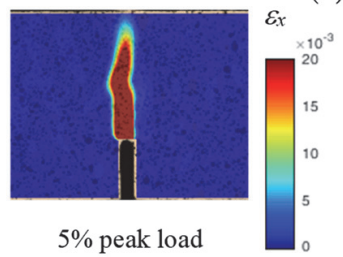

(c)

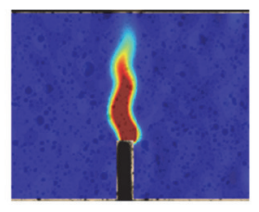

$10 \%$ peak load

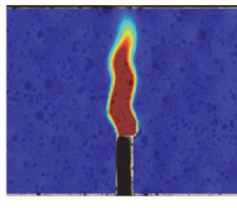

$5 \%$ peak load

Figure 20: Distribution of horizontal strain $\varepsilon_{x}$ field around the notch at different loading level of 3PBT post-peak stage for: (a) N 0\% - Sample 1; (b) N 1\% - Sample 1 and (c) N 2.5\% - Sample 1.

\section{CONCLUSIONS}

7 his work explores the possibility of using biochar obtained through a standardized process of gasification at $700{ }^{\circ} \mathrm{C}$ of wood waste in cement pastes and mortars, with different percentages of addition with respect to the weight of cement, in order to improve the mechanical properties and reduce the carbon footprint of cement.

Based on the experimental results, the following conclusions can be drawn:

- The results of the mechanical tests show that the addition of biochar in a proper percentage increases the flexural strength and generates a more ductile behavior of cementitious composites.

- In terms of flexural strength and fracture energy, the percentage of addition of $2 \%$ of Gray Borgotaro biochar seems to be the most suitable to be used as filler in cement paste mixtures, since it enables to enhanced these properties (e.g. at 7 days, obtaining an improvement of more than $15 \%$ and $150 \%$ respectively). Notwithstanding, the use of biochar in smaller percentages does not produce significant positive effect on mechanical properties of cement pastes. It is concluded that the Gray Borgotaro biochar acts as a micro-reinforcement in the cement paste, which helps to deflect the trajectory of the fracture, generating multiple fractures. This results in a ductile failure when $2 \%$ is used.

- In relation to the cement paste specimens where the cement was replaced by biochar, it is possible to obtain a great increase in the fracture energy performance even when the flexural strength is lower compared to the plain cement paste. Additionally, the replacement of cement in cementitious paste mixtures translates into lower emissions of $\mathrm{CO}_{2}$ into the atmosphere due not only to the lower amount of cement used, but also to the use of biochar itself, since the latter can be considered a method of carbon sequestration. The use of biochar contributes to the fact that bio-materials derived from waste could be accepted as an optimal solution for the reduction of greenhouse gases emissions in the implementation and production of construction materials. 
- As regards mortars, addition of $2.5 \%$ of Gray Borgotaro biochar leads to a general increase of both flexural strength and fracture energy, while conserving a good compressive strength and workability. Nevertheless, this last property is affected when more than $2.5 \%$ biochar is used, hindering the casting process and requiring modifications in the mix design. In particular, in this case, the amount of superplasticizer required becomes higher than that recommended by the regulations (more than $2 \%$ ) and the mixture tends to segregate. On the other hand, by increasing the amount of water, the mixture workability is greatly enhanced, but mechanical strengths decrease considerably. Hence, the set of cement pastes and mortars with the addition of more than $2.5 \%$ of biochar was completely discarded.

This study hopes to generate motivation for future research that explores the use of biochar from different sources in cementitious material, such as pastes, mortars and concretes, since its employment in selected percentage can lead to enhanced mechanical properties, without compromising the workability. Both its use as filler and as cement replacer demonstrate that waste-derived materials can be regarded as an optimal solution for the reduction of greenhouse gases in the production of construction materials.

Finally, a great advantage of biochar is that its use in cement-based materials does not require any special technique or sophisticated configuration that many developing countries cannot apply. In addition, until biochar is not commercially exploited, it continues to be, in many cases a free material with great benefits, or rather, a waste to be disposed with costs.

\section{REFERENCES}

[1] Watts, J. (2019). Concrete: the most destructive material on Earth, Guard., pp. 1-11.

[2] Andrew, R.M. (2017). Global CO2 emissions from cement production, Earth Syst. Sci. Data Discuss., pp. 1-52, DOI: $10.5194 /$ essd-2017-77.

[3] Suhendro, B. (2014). Toward green concrete for better sustainable environment, Procedia Eng., 95(Scescm), pp. 305320, DOI: $10.1016 /$ j.proeng.2014.12.190.

[4] Lothenbach, B., Scrivener, K., Hooton, R.D. (2011). Supplementary cementitious materials, Cem. Concr. Res., 41(12), pp. 1244-1256, DOI: 10.1016/j.cemconres.2010.12.001.

[5] Chen, L., Wang, L., Cho, D.W., Tsang, D.C.W., Tong, L., Zhou, Y., Yang, J., Hu, Q., Poon, C.S. (2019). Sustainable stabilization/solidification of municipal solid waste incinerator fly ash by incorporation of green materials, J. Clean. Prod., 222, pp. 335-343, DOI: 10.1016/j.jclepro.2019.03.057.

[6] Hicks, J.K., Caldarone, M.A., Bescher, E. (2015). Opportunities from Alternative Cementitious Materials, Concr. Int., 37(4), pp. 47-51.

[7] Provis, J.L. (2018). Alkali-activated materials, Cem. Concr. Res., 114, pp. 40-48, DOI: $10.1016 /$ j.cemconres.2017.02.009.

[8] Gartner, E., Sui, T. (2018). Alternative cement clinkers, Cem. Concr. Res., 114, pp. 27-39, DOI: $10.1016 /$ j.cemconres.2017.02.002.

[9] International Biochar Initiative. (2015). Standardized Product Definition and Product Testing Guidelines for Biochar That Is Used in soil. Available at: https://www.biochar-international.org/wpcontent/uploads/2018/04/IBI_Biochar_Standards_V2.1_Final.pdf.

[10] Eurostat. (2020). Treatment of waste by waste category, hazardousness and waste management operations.

[11] Duku, M.H., Gu, S., Hagan, E. Ben. (2011). Biochar production potential in Ghana - A review, Renew. Sustain. Energy Rev., 15(8), pp. 3539-3551, DOI: 10.1016/j.rser.2011.05.010.

[12] Igalavithana, A.D., Choi, S.W., Dissanayake, P.D., Shang, J., Wang, C.H., Yang, X., Kim, S., Tsang, D.C.W., Lee, K.B., Ok, Y.S. (2020). Gasification biochar from biowaste (food waste and wood waste) for effective CO2 adsorption, J. Hazard. Mater., 391(May 2019), pp. 121147, DOI: 10.1016/j.jhazmat.2019.121147.

[13] Agegnehu, G., Srivastava, A.K., Bird, M.I. (2017). The role of biochar and biochar-compost in improving soil quality and crop performance: A review, Appl. Soil Ecol., 119(October 2016), pp. 156-170, DOI: $10.1016 /$ j.apsoil.2017.06.008.

[14] Gonzaga, M.I.S., Mackowiak, C., de Almeida, A.Q., de Carvalho Junior, J.I.T., Andrade, K.R. (2018). Positive and negative effects of biochar from coconut husks, orange bagasse and pine wood chips on maize (Zea mays L.) growth and nutrition, Catena, 162(October 2017), pp. 414-420, DOI: 10.1016/j.catena.2017.10.018.

[15] Alvarez-Campos, O., Lang, T.A., Bhadha, J.H., McCray, J.M., Glaz, B., Daroub, S.H. (2018). Biochar and mill ash improve yields of sugarcane on a sand soil in Florida, Agric. Ecosyst. Environ., 253(November 2017), pp. 122-130, 
DOI: $10.1016 /$ j.agee.2017.11.006.

[16] Thangarajan, R., Bolan, N.S., Kunhikrishnan, A., Wijesekara, H., Xu, Y., Tsang, D.C.W., Song, H., Ok, Y.S., Hou, D. (2018). The potential value of biochar in the mitigation of gaseous emission of nitrogen, Sci. Total Environ., 612, pp. 257-268, DOI: 10.1016/j.scitotenv.2017.08.242.

[17] Qian, K., Kumar, A., Patil, K., Bellmer, D., Wang, D., Yuan, W., Huhnke, R.L. (2013). Effects of biomass feedstocks and gasification conditions on the physiochemical properties of char, Energies, 6(8), pp. 3972-3986, DOI: $10.3390 /$ en6083972.

[18] Zhao, B., O’Connor, D., Zhang, J., Peng, T., Shen, Z., Tsang, D.C.W., Hou, D. (2018). Effect of pyrolysis temperature, heating rate, and residence time on rapeseed stem derived biochar, J. Clean. Prod., 174, pp. 977-987, DOI: 10.1016/j.jclepro.2017.11.013.

[19] Roberts, K.G., Gloy, B.A., Joseph, S., Scott, N.R., Lehmann, J. (2010). Life cycle assessment of biochar systems: Estimating the energetic, economic, and climate change potential, Environ. Sci. Technol., 44(2), pp. 827-833, DOI: $10.1021 /$ es902266r.

[20] Gupta, S., Kua, H.W. (2017). Factors Determining the Potential of Biochar As a Carbon Capturing and Sequestering Construction Material: Critical Review, J. Mater. Civ. Eng., 29(9), pp. 04017086, DOI: $10.1061 /$ (asce)mt.1943-5533.0001924.

[21] Gupta, S., Kua, H.W., Low, C.Y. (2018). Use of biochar as carbon sequestering additive in cement mortar, Cem. Concr. Compos., 87, pp. 110-129, DOI: 10.1016/j.cemconcomp.2017.12.009.

[22] Akhtar, A., Sarmah, A.K. (2018). Novel biochar-concrete composites: Manufacturing, characterization and evaluation of the mechanical properties, Sci. Total Environ., 616-617, pp. 408-416, DOI: 10.1016/j.scitotenv.2017.10.319.

[23] Falliano, D., De Domenico, D., Sciarrone, A., Ricciardi, G., Restuccia, L., Ferro, G., Tulliani, J.M., Gugliandolo, E. (2020). Influence of biochar additions on the fracture behavior of foamed concrete, Frat. Ed Integrita Strutt., 14(51), pp. 189-198, DOI: 10.3221/IGF-ESIS.51.15.

[24] Cuthbertson, D., Berardi, U., Briens, C., Berruti, F. (2019). Biochar from residual biomass as a concrete filler for improved thermal and acoustic properties, Biomass and Bioenergy, 120, pp. 77-83, DOI: $10.1016 /$ j.biombioe.2018.11.007.

[25] Restuccia, L., Ferro, G.A. (2016). Promising low cost carbon-based materials to improve strength and toughness in cement composites, Constr. Build. Mater., 126, pp. 1034-1043, DOI: 10.1016/j.conbuildmat.2016.09.101.

[26] Restuccia, L., Ferro, G.A. (2018). Influence of filler size on the mechanical properties of cement-based composites, Fatigue Fract. Eng. Mater. Struct., 41(4), pp. 797-805, DOI: 10.1111/ffe.12694.

[27] Khushnood, R.A., Ahmad, S., Restuccia, L., Spoto, C., Jagdale, P., Tulliani, J.M., Ferro, G.A. (2016). Carbonized nano/microparticles for enhanced mechanical properties and electromagnetic interference shielding of cementitious materials, Front. Struct. Civ. Eng., 10(2), pp. 209-213, DOI: 10.1007/s11709-016-0330-5.

[28] Gupta, S., Kua, H.W., Tan Cynthia, S.Y. (2017). Use of biochar-coated polypropylene fibers for carbon sequestration and physical improvement of mortar, Cem. Concr. Compos., 83, pp. 171-187, DOI: 10.1016/j.cemconcomp.2017.07.012.

[29] Gupta, S., Kua, H.W., Koh, H.J. (2018). Application of biochar from food and wood waste as green admixture for cement mortar, Sci. Total Environ., 619-620, pp. 419-35, DOI: 10.1016/j.scitotenv.2017.11.044.

[30] Gupta, S., Kua, H.W., Pang, S.D. (2018). Healing cement mortar by immobilization of bacteria in biochar: An integrated approach of self-healing and carbon sequestration, Cem. Concr. Compos., 86, pp. 238-254, DOI: $10.1016 /$ j.cemconcomp.2017.11.015.

[31] Gupta, S., Kua, H.W., Pang, S.D. (2018). Biochar-mortar composite: Manufacturing, evaluation of physical properties and economic viability, Constr. Build. Mater., 167, pp. 874-889, DOI: 10.1016/j.conbuildmat.2018.02.104.

[32] Belletti, B., Bernardi, P., Malcevschi, A., Sirico, A. (2019).Experimental research on mechanical properties of biocharadded cementitious mortars. CONCRETE Innovations in Materials, Design and Structures: Proceedings of the fib Symposium 2019, Kraków, Poland 27-29 May 2019, FIB-Féd. Int. du Béton.

[33] Gupta, S., Kua, H.W. (2018). Effect of water entrainment by pre-soaked biochar particles on strength and permeability of cement mortar, Constr. Build. Mater., 159, pp. 107-125, DOI: 10.1016/j.conbuildmat.2017.10.095.

[34] Gray, M., Johnson, M.G., Dragila, M.I., Kleber, M. (2014). Water uptake in biochars: The roles of porosity and hydrophobicity, Biomass and Bioenergy, 61, pp. 196-205, DOI: 10.1016/j.biombioe.2013.12.010.

[35] Li, F., Cao, X., Zhao, L., Wang, J., Ding, Z. (2014). Effects of mineral additives on biochar formation: Carbon retention, stability, and properties, Environ. Sci. Technol., 48(19), pp. 11211-7, DOI: 10.1021/es501885n.

[36] (2019). Fairchildite Mineral Data. Available at: http://www.webmineral.com/data/Fairchildite.shtml\#.XNH25Ogzbid. [accessed May 20, 2019]. 
[37] (2000). JCPDS cardo 021-1287. International Centre for Diffraction Data.

[38] Humphreys, G.S., Shakesby, R.A., Doerr, S.H., Blake, W.H., Wallbrink, P., Hart, D.M. (2003). Some effects of fire on the regolith, Adv. Regolith, , pp. 216-20.

[39] Brunauer, S.; Emmett, P.; Teller, E. (1938). Adsorption of Gases in Multimolecular Layers, , J. Am. Chem. Soc., 60, pp. 309-3019, DOI: https://DOI-org.ezproxy.biblio.polito.it/10.1021/ja01269a023.

[40] Restuccia, L., Reggio, A., Ferro, G.A., Kamranirad, R. (2017). Fractal analysis of crack paths into innovative carbonbased cementitious composites, Theor. Appl. Fract. Mech., 90, pp. 133-141, DOI: 10.1016/j.tafmec.2017.03.016.

[41] Cosentino, I., Restuccia, L., Ferro, G.A., Tulliani, J.M. (2018). Influence of pyrolysis parameters on the efficiency of the biochar as nanoparticles into cement-based composites, Procedia Struct. Integr., 13, pp. 2132-2136, DOI: 10.1016/j.prostr.2018.12.194.

[42] Sirico, A., Bernardi, P., Belletti, B., Malcevschi, A., Dalcanale, E., Domenichelli, I., Fornoni, P., Moretti, E. (2020). Mechanical characterization of cement-based materials containing biochar from gasification, Constr. Build. Mater., 246, pp. 118490, DOI: 10.1016/j.conbuildmat.2020.118490.

[43] Schwartzentruber, A., Catherine, C. (2000). La méthode du mortier de béton équivalent (MBE)—Un nouvel outil d'aide à la formulation des bétons adjuvantés, Mater. Struct., 33(8), pp. 475-82, DOI: 10.1007/s11340-015-0009-1.

[44] (2016). EN 196-1:2016. Methods of testing cement - Part 1: Determination of strength.

[45] (1985). RILEM Draft Recommendation . Determination of fracture energy of mortars and concrete by means of threepoint bend tests on notched beams, Mater. Struct., 18, pp. 285-90.

[46] (2003). JCI-S-001-2003. Method of test for fracture energy of concrete by use of notched beam. 